NASA Technical Memorandum 85913

NASA-TM-85913

19850002624

\title{
Role of Research Aircraft in Technology Development
}

\section{Kenneth J. Szalai}

LIBRAM GMPV

1.1 1984

LANGLEY RESEARCH CENTER

LIBRARY, NASA

HAMPTON, VIRGINIA' 


\section{Role of Research Aircraft in Technology Development}

Kenneth J. Szalai

Ames Research Center, Dryden Flight Research Facility, Edwards, California

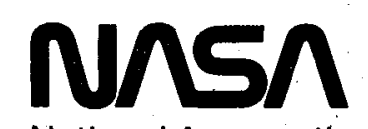

National Aeronautics and

Space Administration

Ames Research Center

Dryden Flight Research Facility

Edwards, California 93523 
ROLE OF RESEARCH AIRCRAFT IN TECHNOLOGY DEVELOPMENT

\author{
Kenneth J. Szalai* \\ NASA Ames Research Center \\ Dryden Flight Research Facility \\ Edwards, California
}

\section{Abstract}

The United States' aeronautical research program has been rich in the use of research aircraft to explore new flight regimes, develop individual aeronautical concepts, and investigate new vehicle classes and configurations. This paper reviews the NASA supercritical wing, digital fly-by-wire, HIMAT, and $A D-1$ oblique-wing flight research programs, and draws from these examples general conclusions regarding the role and impact of research aircraft in technology development. The impact of a flight program on spinoff technology is also addressed. These secondary, "serendipitous" results are often highly significant. Finally, future research aircraft programs are examined for technology trends and expected results.

\section{Introduction}

The history of research and experimental aircraft in the United States is a rich one. Figure 1 shows some of the research and experimental aircraft that have been flown at the Ames Research Center, Dryden Flight Research Facility, at Edwards, California. These aircraft have ranged from exotic forms designed to expand the overall knowledge of aerodynamic configurations, to complex systems atrcraft designed to explore improved efficiency or improved mission effectiveness. Some of these aircraft were forerunners of military aircraft; others, such as the Lunar Landing Research Vehicle which prepared astronauts for lunar landings, were important trainers.

Flight research has been a vital and continuous part of this nation's aeronautical research program since the inception of the National Advisory Committee on Aeronautics (NACA) in 1915. Flight research with both highly modified service aircraft and new experimental aircraft has contributed to many of the aeronautical advances over the past several decades, drawing on a strong partnership between NACA/NASA, the Department of Defense (DOD), and industry. The nature of research aircraft has changed over the years, reflecting the change in the aeronautical research thrusts of the nation. In recent years, research aircraft programs have focused on aeronautical improvements within the flight envelope explored by the $x$-series aircraft.

This paper explores the recent past and examines the roles of various research aircraft in technology development. It also looks into the future, examining upcoming experimental and research aircraft that will play a major role in focusing the aeronautical research programs of this country.

\footnotetext{
*Chief, Research Engineering Division. Member AIAA.
}

This paper is declared a work of the U.S. Government and therefore is in the public domain.
Types of Research Aircraft

There is an extremely wide range of research and experimental aircraft, each contributing in its own way to aeronautical technology. The following sections summarize various types of research aircraft, giving examples of aircraft in each category.

\section{Exploratory Research Aircraft}

The most well known and certainly most spectacular research aircraft are those that have been designed to explore new flight regimes. The most significant flight research activity in this nation's history took place with the rocket-powered $X$-series aircraft $(X-1, D 558-I I, X-2$, and $X-15)$, which were designed to explore high-speed and high-altitude flight. Most of these aircraft had little or no wind tunnel predictions. Research aircraft were the only way to get data. These aircraft were really probing the unknown.

The $x$-aircraft program continuously expanded the flight envelope of manned aircraft, and was embodied in the "higher and faster" thrust of the early years of rocket and jet aircraft. The first of these aircraft was the $x-1$ (Fig. 2), which on October 14, 1947, became the first aircraft to exceed the speed of sound in level flight. By far the most successful of all the research aircraft was the $X-15$ (Fig. 3), which reaches a speed of Mach 6.7 and an altitude of $354,200 \mathrm{ft}$. Table 1 summarizes the expansion of the manned flight envelope by the $x$-series aircraft during an amazingly few number of years. 1 In addition to establishing an aeronautical data base, this series of flight tests supported the manned space program, including the space shuttle. For example, the $\mathrm{x}-15$ testing perfected reaction-controlled flight at altitudes well over 50 miles and demonstrated clearly the ability to return such an aircraft to a precision unpowered landing. The $x-15$ program was a national effort, combining the best industry, military, and NASA personnel, and was the centerpiece of aeronautical research for nearly a decade.

The Dyna-Soar program was intended to continue to expand the manned flight envelope, but it was canceled. Several small-scale unmanned vehicles, such as ASSET and PRIME, explored the extreme hypersonic flight envelope, and the space shuttle finally expanded the flight envelope to orbital. velocities.

\section{New Vehicle Classes}

Some research aircraft are designed to explore entirely new vehicle classes. An example of this was the joint NASA/Air Force lifting body program which investigated lifting reentry shapes. In this program, configurations developed by NASA Ames, NASA Langley, and DOD were investigated in a series of manned experimental aircraft programs to determine their supersonic and subsonic characteristics. Aerodynamics, stability and control, and 
especially handing qualities in the landing approach were investigated. The lifting bodies flown (Fig. 4) included the lightweight M2, the hea vyweight $M 2-F 2$, the $H L-10$, and the $X-24$ aircraft. The $x-24 \mathrm{~B}$ aircraft (Fig. 5), the last of the lifting bodies, had an advanced hypersonic shape and a good hypersonic lift-to-drag ratio, and demonstrated the ability to achieve pinpoint landings on a hard runway, paving the way for unpowered shuttle landings on the same runway a few years later. This program was highly exploratory and highly successful in producing a data base for lifting reentry vehicles.

An entire series of $x$-aircraft has been devoted to exploration of vertical and short takeoffs and landings. ${ }^{2}$ This series included aircraft such as the $x-13, x-14, x V-5 A, x C-142, x-22$, and most recently, the successful $x V-15$ tilt rotor aircraft.

\section{New Aerodynamic Concepts and Configurations}

The aircraft that have explored new aerodynamic concepts and configurations have included the $x-3$, originally designed to explore the problems of sustained supersonic flight; the $\mathrm{x}-4$, designed to investigate the stability and control characteristics of a tailless, swept-wing configuration; the $x-5$, the first aircraft with a variable-sweep wing; and the $X F-92 \mathrm{~A}$, intended to study the deltawing concept. More recent examples include the remotely piloted highly maneuverable aircraft technology (HIMAT) vechicle and the oblique-wing AD-1 aircraft, which are discussed in some detail in subsequent sections of this paper. Another example of this class of aircraft, which shares $\mathrm{X}$-airplane characteristics, is the $x-29$ forward-swept wing aircraft. Although using major elements of operational aircraft, such as forebody and gear, it represents a substantially new and unique aerodynamic configuration. These aircraft were not designed to break speed or altitude records, but rather to explore new aerodynamic concepts within the flight regimes established by earlier aircraft.

\section{Derivative Experimental and Research Aircraft}

Following the demise of the $\mathrm{x}$-airplane program, aeronatical flight research activities shifted to the less expensive mode of using extensively modified operational aircraft to explore a concept or system that could be incorporated without fabricating an entirely new aircraft. Examples in this class include the F-8 supercritical wing aircraft, the F-111 transonic aircraft technology (TACT) vehicle, the $\mathrm{KC}-135$ winglet aircraft, and the advanced fighter technology integration (AFTI) F-111 aircraft. Not only aerodynamic concepts have been explored in this manner. The F-8 digital fly-by-wire and AFTI/F-16 research aircraft were used to investigate advanced digital fly-by-wire control, and the Firebee II served as a carrier aircraft to explore active flutter suppression in the drones for aerodynamic and structural testing (DAST) program.

\section{Basic Research Test-Bed Aircraft}

Research aircraft have also been used as test beds to explore fundamental aspects of fluid mechanics and aerodynamics. This type of research aircraft is generally intended to carry piggyback experiments, conducting research that is narrow in scope; the vehicle itself is generally not involved in the experiment. For example, an F-15 aircraft at the NASA Ames-Dryden Flight Research Facility was used to carry a loft a precision $10^{\circ}$ cone that has been used as an international wind tunnel calibration device (Fig. 6 (a)). In this experiment, transition Reynolds number was measured in flight to produce a standard for levels of free-air turbulence (Fig. 6 (b)). In another experiment (Fig. 7), a large cylinder was carried to high supersonic speeds by a NASA YF-12 aircraft, in a flying wind tunnel experiment. The cylinder was precooled with Iiquid nitrogen. When the test condition was reached, an insulated covering was blown off and heating effects were measured precisely.

Currently, an F-104 aircraft, modified to carry a special flight test fixture (Fig. 8), is being used to conduct aerodynamic experiments. Figure 9 shows the dynamic pressure and Mach number regime through which this experimental fixture can be carried. The aircraft has also been modified to permit it to fly complex Mach number and dynamic pressure profiles, such as a constant Reynolds number profile (Fig. 9).

\section{Variable Stability Aircraft}

A special class of aircraft has been very important to the stability and control and handing qualities research in this country. Not research aircraft in the classical sense, these aircraft, known as variable stability aircraft, have produced the greatest share of data from which specifications for military flying qualities and other dynamic and control design guides have been derived. Vehicles such as the Casspan B-26, T-33, Total In-Flight Simulator (TIFS, Fig. 10), and $x-22$, as well as Government-operated aircraft such as the Ames $\mathrm{X}-14$ and the JetStar General Purpose Airborne Simulator, have contributed substantially to the understanding of flying qualities, motion-cue effects, simulation fidelity requirements, and man-machine dynamic effects.

\section{Case Studies of Recent Research Aircraft}

Brief case studies of the F-8 supercritica 1 wing, F-8 digital fly-by-wire, HiMAT, and AD-1 oblique-wing flight research programs are examined for their technology contributions.

\section{Supercritical wing Technology}

The approach used in the supercritical wing experiment was to duplicate the NASA wind tunnel wing design in a large-scale experiment using an F-8 aircraft ${ }^{3}$. The wing was designed to match the wind tunnel shape and conditions, and was aeroelastically tailored to achieve these conditions in flight at the design point. In addition, the flight experiment was designed to study the offdesign performance of the wing through the subsonic and supersonic flight envelope.

Background. The development of the subsonic fet transport in the late fifties and early sixties literally revolutionized world air travel. The door was opened to rapid transcontinental and intercontinental air transportation. As a result, world distances shrunk from days and weeks, to hours. The mid-60s saw aeronautical researchers turn their attention to further increases in jet transport aircraft efficiency. As this research 
pushed cruise speeds higher and higher, new problems were encountered which adversely affected performance.

Perhaps the best known of these was the large discrepancy in the wing shock-wave location (Fig. 11) between wind tunnel and flight data obtained for a large transport aircraft at transonic speeds. The possible effect of this discrepancy on the accurate prediction of loads, stability, and performance for this type of aircraft provided the impetus for new studies to resolve the difference.

One of the early leaders in this area of research was NASA's Dr. Richard T. Whitcomb. Dr. Whitcomb theorized that the disproportionate boundary layer thickness at the trailing edge of the model wing was the parameter primarily responsible for determining shock-wave location and the resulting pressure distribution. Additional research by Blackwell led to the establishment of a boundary layer scaling criterion for airfoils with different pressure distributions.

Armed with these research results, Dr. Whitcomb turned his attention from the supersonic transport configuration development and set as a goal efficient Mach 1 cruise capability. Whitcomb initiated and led research efforts that resulted in the development of the supercritical airfoil, a shape that provided significant increase in critical Mach number by minimizing wave drag (Fig. 12).

F-8 Flight Experiments. The potential benefits of the supercritical airfoil were dramatic. However, the data previousiy noted for the transport aircraft caused many to question the validity of Whitcomb's low-Reynolds-number wind tunnel results. To substantiate the supercritical wing data, several flight experiments were initiated, the most noteworthy being those performed on the F-8 supercritical wing research airplane (Fig. 13). This research airplane was a highly modified $\mathrm{F}-8 \mathrm{C}$ incorporating a new swept transport type supercritical wing and fuselage area ruling to demonstrate the delayed drag rise of the supercritical airfoil and address the concerns associated with shockboundary layer interactions and near sonic cruise. Both wind tunnel and flight data were obtained to compare and evaluate performance, stability and control, and handling qualities. In addition. detailed pressure distribution data were obtained to assess Reynolds number effects.

The pressure distribution and drag measurements obtained for this configuration at subcritical conditions agreed well with wind tunnel predictions. As sonic velocities were reached, however, the pressure distribution data comparison was not so good. The upper-surface second velocity peaks (Fig. 14) were greater in magnitude and occurred farther aft in flight than in the wind tunnel. This discrepancy was attributed to the fact that the configuration was developed in an environment affected by wind tunnel walls. The result of this discrepancy was a slight (0.01 Mach) decrease in the cruise flight Mach number (Fig. 15). These results were unexpected at the time because all the generally accepted practices for dealing with wind tunnel wall and blockage effects were used.
The F-8 supercritical wing research program was an extremely important activity for the Agency as well as for the DOD and the aerospace community. Performance benefits as well as the validity of the design approach in achieving superior transonic performance with this radical airfoil design was demonstrated. Test results in the high-Reynoldsnumber regime, as well as over a wide range of maneuvering and subsonic and supersonic flight, provided confidence that this airfoil design could achieve many of the benefits that had been predicted in wind tunnel and analytical tests. The program not only provided a credible design data base for commercial and military aircraft, it provided spinoff technology in new criteria for testing at transonic speeds to properly account for wind tunnel wall effects, model blockage effects, and condensation effects.

Technology Spinoff. The F-8 SCW program required an accurate Mach number mea surement near Mach 1. This led to the development of a compensated air data probe which produced a flight Mach number measurement accurate to within \pm 0.003 . As a result, the SCW flight data base at or near Mach 1 was quite unique in its accuracy. The program also included wing boundary layer and wing wake surveys at flow conditions where the analytically derived flow equations break down. These wing boundaxy layer and wake surveys were only obtained in flight. The wing wake surveys, with and without boundary layer trips, also suggested that a region of laminar flow existed on the wing near Mach 0.97. This was a significant unexpected finding and indicated that natural laminar. flow could be achieved at high subsonic speeds for a small leading edge radius supercritical wing.

The effects of using externally mounted pressure tubing to obtain pressure distributions were also evaluated on the F-8 SCW airplane. These results were compared with the flush orifice data, and it was established that this relatively simple and inexpensive technique can produce reliable pressure distribution results relative to trends and levels up to Mach 0.97 .

Follow-on Flight Experiments. In the military applications area, a subsequent experiment, the F-111 TACT program, explored supercritical wing technology in maneuvering flight with high-lift devices also designed for the wing. The results from the F-8 supercritical wing research airplane, the F-111 TACT research airplane, and a thick supercritical wing modification to a Navy T2-C airplane provided flight validation of the practicality of using supercritical airfoils to provide significant increases in cruise Mach number, maneuverability, and structural efficiency of aircraft. Subsquent to the F-111 TACT experiment, an advanced supercritical airfoil with smooth, variable-camber leading and trailing edges was designed to explore the potential of in-flight adaptable wing camber in the AFTI/F-111 mission adaptive wing (MAW) program. The utility of a thin supercritical wing for fighter aircraft will be explored in the $x-29$ forward-swept wing program.

\section{F-8 Digital Fly-By-Wire Program}

NASA's flight research program to explore failure-tolerant digital fly-by-wire (DFBW) control 
for aircraft is an example of flight research on an advanced aeronautical concept that did not require changes to the external configuration of the aircraft. The feasibility of digital fly-by-wire control for aircraft was first established using the guidance, navigation, and control system of the Apollo lunar module installed in an F-8 aircraft at the Ames-Dryden Flight Research Facility. ${ }^{4}$ In 1972 the F-8 aircraft became the first digital fly-bywire aircraft to be flown without mechanical reversion (Fig. 16). The second phase of this program, using an experimental triplex system, was designed to produce an extensive data base for multichannel fault-tolerant digital fly-by-wire control ${ }^{5}$.

The approach used in both phases of the flight program was to build an experimental digital fly-bywire research control system as the primary flight control system for the research aircraft. Thus the primary flight control system was also the experiment. Research experiments included investigations of advanced redundancy management techniques and control law mechanizations, as well as implementation technology involving multichannel hardware and sof tware.

Technology Contributions. The contributions of this program to DFBW technology have been significant. First, redundancy management techniques were developed, tested, and validated for multichannel computers, sensors, actuators, and cockpit displays and controls, producing both the techniques and the confidence that these techniques could be used to achieve truly fault-tolerant systems. The ability of such systems, which have full-time and fullauthority control over the aircraft, to tolerate actual hardware faults and to have a high immunity to nuisance failures was demonstrated over several years of flight test.

Another contribution to technology was the interfacing of an independent analog backup control system to a digital primary flight control system, an approach that continues to be used in several applications today. Significant results and experience were also achieved in the area of verification, validation, and flight qualification techniques for full-authority flight control systems employing digital primary flight control computers. ${ }^{6}$ Software verification and testing techniques, as well as failure modes and effects test approaches, were developed and continue to be used today.

In the area of control law design, direct digital control and digital optimal control were used to develop advanced control laws that were evaluated under a variety of cruise and maneuvering flight conditions. Such direct digital control design represented a departure for aircraft control system design practice in that the design did not start from a continuous control system baseline. The F-8 digital fly-by-wire program also validated reliability prediction for multichannel digital Elight control systems and produced techniques for analyzing the reliability of these complex systems. ${ }^{7}$ Figure 17 shows the final predictions of the as-built DFBW system.

The basic F-8 digital fly-by-wire experiment was of ficially completed in 1980, following 7 years of flight testing with two digital fly-by-wire control systems. However, this research aircraft continues to be an important flying facility for advanced experiments. Subsequent to the basic DFBW experiment, experiments in advanced control law and redundancy management techniques were conducted on the $F-8$ aircraft. Adaptive control, using real-time parameter estimation, and analytic redundancy management, ${ }^{8}$ using dynamic and kinematic relationships between the flight control sensors, were evaluated in flight.

The F-8 digital fly-by-wire aircraft was also used to systematically explore the effects of pure transport time delay on flying qualities for the first time in an actual flight regime. 9 Flying qualities and stability and control effects for the total pilot-vehicle system were examined in maneuvering flight, in formation flight, and finally, during actual approaches and landings. These results are unique in that it has not been possible to reproduce in simulators the levels of pilot gain experienced in flight for these kinds of conditions. The data in Fig. 18 indicate the dramatic effect of time delay in low-gain and high-gain tasks. The high-gain task is a natural result of a single pilot in a real aircraft flying a real mission.

Spinoff Techinology. Besides the many successes and technology contributions that resulted in areas being specifically investigated, there were many unexpected results and spinoffs from this program. One unexpected result in the early 1970s was the extraordinarily high burden of sof tware verification and validation for aircraft digital fly-by-wire control systems. In addition, despite extremely rigorous and complete ground testing in several facilities, system anomalies continued to be found after the flight program commenced (Fig. 19). Although none resulted in an in-fight problem, this finding has had a sobering effect on the design of digital fly-by-wire control systems for current aircraft as ways are sought to protect against generic design or implementation errors.

A significant fallout of the $F-8$ digital fly-by wire flight program was the development of an in-depth and complete characterization of the faulttolerant and operational features of this multichannel digital system. This complete understanding resulted because every anomaly that occurred in this flight-crucial system required intense and complete investigation and understanding betore further flight. This intense investigation rarely occurs in the laboratory environment, but is a natural result of placing a flight-crucial system into a research aircraft.

A spinoff of the adaptive control law experiment was a new flight test technique that uses the AmesDryden remotely piloted vehicle ground facility to uplink and downlink data between a ground computer and the aircraft (Fig, 20). Advanced control laws can be programmed on the ground computer and used to control the F-8 aircraft in flight; however, the pilot can revert to the F-8 DFBW onboard control system at any time. This technique has become an important research capability in its own right by providing a low-cost, high-quality means of conduct-. ing speculative and high-risk flight control law research, as well as providing a means of improving flight test program efficiency through uplink control.

Several NASA scientists and engineers, universities, and industry research departments 
participated in the design aspects of the program, to provide practical algorithms to be flown on the F-8 aircraft. Designs and design approaches matured as the designers attempted to apply highly speculative and analytical approaches to real problems, and hence discovered areas needing continued research. This program also produced a core expertise that outlived the original experiments and continues to contribute to other digital fly-bywire system developments.

Confidence in Technology. Today the step from mechanical controls to digital fly-by-wire for aircraft seems a trivial and logical one. However, in the late 1960s, such a step was considered to be extremely speculative and very high risk. The F-8 digital fly-by-wire program made two significant contributions to this technology: (1) a solid design base of techniques that work and those that do not, and (2) credible evidence of good flying qualities and the ability of such a system to tolerate real faults and to continue operation without degradation. The combination of the technical data and demonstration of flight control system performance was a powerful argument for use of this technology in other aircratt. The transition from mechanical controls to pure electronic controls was an extremely emotional issue; this program, as well as the companion Air Force F-4 analog fly-bywire program, were instrumental in providing the confidence in the technology being applied today. DFBW systems have also enabled a whole new range of aircraft design approaches to be considexed, which is in itself an important technology development.

\section{HiMAT Program}

The HiMAT program was conceived in the early 1970 s.10-12 The philosophy of the HiMAT program was similar to that of the $x$-aircraft programs in that an entirely new aircraft was developed for the research program (Fig. 21). In this case, the aircraft was unmanned and scaled. A major objective of this program was to explore the deliberate design interaction and integration of new technologies to significantly improve maneuvering and cruise performance over that of contemporary aircraft. A specific goal was to achieve twice the maneuvering capability of aircraft of the mid1970s. A secondary objective was to explore the use of scaled, remotely piloted research vehicles as a means of providing a high-quality, credible data base for the design of advanced highperformance aircraft.

The research approach was to design a fullscale highly maneuverable aircraft, and then design a scaled flight version of that aircraft to explore and demonstrate the technologies incorporated in the full-scale design. Those technologies included a close-coupled canard/wing configuration, relaxed static stability, graphite epoxy composite structures for reduced weight, aeroelastic tailoring to provide the optimum maneuvering shape, digital flyby-wire control, digital engine control, advanced propulsion system modes, microprocessor-implemented flight controls, advanced aerodynamic design for both the wing and canard, and a two-position variable-camber leading edge.

Flight Research Program. The program produced a 3500-1b, 0.44-scale jet-powered remotely piloted research vehicle with a high degree of completeness in representing the full-scale aircraft (Fig. 22).
The aircraft was designed to fly virtually the entire flight envelope of the full-scale aircraft design, with the exception of the takeoff regime. The aircraft was launched from a B-52 aircraft and landed horizontally on skids, controlled from a ground-based facility by a pilot using a forwardlooking television display and flight instruments for landing guidance. The 585 afterburning engine provided the capability to explore both high-g transonic maneuvering flight and supersonic cruise and maneuver conditions.

Many of the detailed results of this program are classified; however, some general results illustrate the quality and significance of the data. First, extremely high levels of maneuvering capability were demonstrated. ' The aircraft was designed to sustain $8 \mathrm{~g}$ flight in the transonic regime at combat altitudes. In Fig. 23, the design goal of this aircraft is illustrated by comparison of its design turn radius with that of operational aircraft of the day. Actual performance of the aircraft was measured using high-g maneuvers to establish the levels of specific excess energy at various flight conditions.

In addition to the direct measures of maneuvering performance, a myriad of research data was obtained. Pressure distributions were obtained over a wide range of Mach numbers for both the wing and the canard (Fig. 24). These data proved extremely valuable in validating both the original computational aerodynamic predictions and more modern codes. This validation was important because the HiMat vehicle was designed using principally computational aerodynamic codes, with only 500 hours of wind tunnel time being used to refine and validate the aerodynamics.

The aeroelastic design of the vehicle was intended to provide an optimum maneuvering shape for the vehicle through the use of a nonstandard bias layup for the graphite composite materials. Detailed measurements of deflection and twist were extracted and compared with design predictions as well as results of ground loads tests. Figure 25 shows an example of the initial NASTRAN predictions and actual twist for the wing. Differences in materials characterization were responsible for the NASTRAN prediction exrors. When new materials characterizations were used in the NASTRAN model, excellent agreement resulted. These data demonstrated the ability to accurately predict deflections and twists for this composite structure.

Associated with the aeroelastic tailoring are the static aeroelastic effects on the stability dexivatives of the aircraft. Using parameter estimation methods, stability derivatives were extracted and compared with analytic and wind tunnel predictions that had been corrected for aeroelasticity. Significant differences were found in the predictions of some parameters measured from flight data (Fig. 26). Because of their significance for future aircraft design, these differences have spawned additional research activities to discover and isolate their cause.

The flight and analytic results also demonstrated the relative benefits of selecting the nonstandard bias layup for the HiMAT vehicle. These data should provide a good data base for future designers as they select both materials and configurations for advanced vehicles (Fig. 27). In 
addition, the flight results showed reduced levels of buffet as compared with other vehicles. These buffet data, along with the pressure distribution and airfoil design, will provide design options for future airoraft.

Technology Spinoff. In addition to the direct technology developments of this program, there were several technology spinoffs, including the development of an extremely. sophisticated and advanced remotely piloted research vehicle facility at the Ames-Dryden Flight Research Facility. This facility, in fact, has become a core element of research programs for both remotely piloted vehicles and manned aircraft. The Controlled Impact Demonstration program, which has various crash-worthiness objectives, is using this facility to conduct a remotely controlled impact test of a large transport aircraft on the lakebed at Edwards AFB.

A surprising result of the flight program was the difficult nature of the steady, high-g, coristant-altitude turn maneuver task for the pilot. This had not been a serious problem in previous manned programs. The lack of motion and peripheral vision cues, combined with the flying qualities of the aircraft, created a task that could not be performed to the accuracy demanded for pressure distribution and performance measurements. This forced the development of a new flight test technique that allowed the maneuvers to be flown automatically. Aerodynamic measurements obtained on the HiMAT vehicle using this technique were excellent. The major factor in this success was the use of the flight test maneuver autopilot, 13,14 which acquired and held flight conditions for the pressure distribution measurements with extreme accuracy and produced extremely repeatable results (Fig. 28). The improvements offered by this maneuver autopilot are illustrated in Fig. 29. This technique is now being applied to manned research aircraft as well, to improve the acquisition of flight data of highperformance research aircraft and to reduce the cost of such testing. A subset of this technique, flight test maneuver guidance, is also used to aid the pilot in manually flying certain complex maneuvers.

A significant and somewhat surprising result of the program was the extremely high quality of research data acquired. A comparison with manned aircraft in similar experiments showed that despite the size and unmanned nature of this vehicle, the quality of the research data was as good as or better than that achieved in the manned full-scale aircraft experiments. The aerodynamic and structural loads and deflections data were of extremely high quality. These data provided a credible data base for correlation with both wind tunnel and analytic predictions, and will continue to provide a basis for judging and improving computational codes. Table 2 summarizes these comparisons for the measurements made on this aircraft.

Another spinoff of the program was the development of a highly accurate electro-optical deflection measurement system. The system was developed because of the need to accurately measure the in-flight deflection and twist of both the canard and wing (Fig. 30). It is also being applied to manned aircraft and aircraft of larger size.
The high workload and difficult nature of the landing task for the pilot was another somewhat surprising result. A.l though the possibility of personal injury was not a factor, the workload was extremely high, requiring a great deal of pilot skill to land the vehicle safely. Even more surprising was that, despite the overall difficulty of the task, all landings were excellent, with no damage to the aircraft (Fig. 31 ).

Flight control system design experience showed that the system burden was very high for controlling an unstable aircraft with a very small time to double amplitude. For the Himat vehicle, this time was approximately $250 \mathrm{msec}$. A design was achieved, however, that was able to control this level of aircraft instability satisfactorily. This required very precise models of the aerodynamics and control system elements to achieve a suitable control system mechanization with adequate stability margins and failure management properties. The flight control system design and development, which applied direct digital design techniques as well as advanced fault-tolerent computational and actuation elements, provided a valuable means for assessing methods required to stabilize a highly unstable vehicle. The experience gained on this design continues to be used today on other unstable aircraft.

Additional payoff. Ground test techniques for the qualification and validation of highly integrated aircraft were also developed for this program. To ensure that all systems on the vehicle were properly interacting and correctly operating prior to flight, the airplane itself was used as an iron bird. The airplane was inserted in the closed loop of a full nonlinear simulation, and the operation of all systems on the aircraft was assessed in an integrated and simultaneous manner (Fig. 32). Specialized ground test equipment was also developed to provide the insight into the total system operation that was required to qualify this velicle for flight. This experience has led to the development of new test techniques, and to a design for a new NASA Integrated Test Facility to facilitate integrated ground test and qualification of advanced research aircraft, which will undoubtedly continue to have more highly interactive and integrated systems.

A very favorable result of the HiMAT program was the extremely high performance of the onboard microprocessor-implemented digital flight control system, which involved multiple interrupt-driven loops performing some functions at rates of

$2420 \mathrm{~Hz}$. A complete flight control system was also implemented using this relatively modest microprocessor technology. Table 3 shows the loop structure and functions of the onboard control computer. This capability was surprising to many.

The experience of industry and Government in conducting the design, development, flight qualification, and flight test of this aircraft has produced a body of experience and data that is being used in other advanced research and development aircraft programs. The major benefit of this program has been the ability to examine, in the real environment, the quality of predictive analyses and the degree of synergism that can be obtained by combining a number of aerodynamic, structural; propulsion, and flight control system technologies. 
The problems in separating the contributions of these technologies also became apparent during the flight test program, and new techniques are being developed to enable such experiments to be conducted on future aircraft.

Lessons Learned. The total vehicle system test and integration activity was not different from that required for a manned research airplane. An interesting facet of the HiMAT program was that the original intent of the program was to consider the aircraft expendable. However, the cost and visibility of the program, as well as the desire to acquire valuable data quickly, made the vehicle more valuable than was originally anticipated. Therefore, development, ground operations, preflight tests, and flight operations differed very iittle from those for manned flight programs at Ames-Dryden. In the area of pilot-vehicle interface, the HiMAT program did not provide the ability to assess the maneuverability of the vehicle in a tactical or mission application. The lack of handling qualities information is a serious drawback of remotely piloted vehicles but must be weighed against the cost of acquiring certain kinds of data in a full-scale research aircraft. NASA and industry studies show that the cost of the HiMAT vehicle was approximately one-third that of a full-scale manned research vehicle incorporating the same technologies (Fig. 33).

One additional factor to be considered in remotely piloted research vehicle design is that this program failed to excite the piloting community within Government and industry. This can represent a serious drawback in terms of overall program advocacy and interest. From a technical viewpoint, however, the program successfully contributed to the various technologies that it was designed to examine.

\section{$A D-1$ Low-Speed Oblique-Wing Research Aircraft}

The approach used in the AD-1 low-speed obliqueming research aircraft program is not unlike that used for the first lightweight lifting body, which was built of plywood at Ames-Dryden at very low cost to examine the low-speed flight regime before committing to a large, manned, highspeed aircraft. In the case of oblique-wing technology, wind tunnel tests had shown potential performance benefits transonically and supersonically when an oblique-wing aircraft was compared with an equivalent variable-sweep aircraft. Aside from uncertainties regarding the aerodynamic performance, there were those related to the low-speed handling qualities of an oblique-wing aircraft, including the ability of a pilot to land an aircraft with a large wing-skew angle; the stability and control of. an oblique-wing aircraft, especially with cross coupling; and finally, dynamics and trim characteristic effects on overall flying qualities.

The approach to investigating these issues was to build a small, low-cost manned research vehicle.15-17 NASA contracted with leading designers and builders of small aircraft to build a foam-and-fiberglass piloted alrcraft powered by two ducted fan turbine engines (Fig. 34). Table 4 summarizes the characteristics of the research aircraft. To keep costs low, light airplane avionics and simple mechanical controls were used. Instrumentation consisted of a 4i-channel pulse-code modulation (PCM) system, with structural and dynamic sensor data telemetered to the NASA ground station. The configuration was tested in the wind tunnel before a commitment was made to flight test. The aircraft was developed for less than $\$ 300,000$.

Flight Research. This low-cost, low-speed manned research aircraft has made significant contributions to oblique-wing technology. First, it produced a wealth of high-quality stability and control and flying qualities data, which were useful in validating predictions of the characteristics of this type of aircraft. For example, the unique cross-coupling terms of oblique-wing aircraft were estimated from flight data (Fig. 35). The side force and trim requirements were also established (Fig. 36). These results, combined with the aeroelastic effects measured, have provided insight into the design requirements for oblique-wing configurations.

Probably more significant than the stability and control characteristics themselves were the handing qualities data obtained. Pilots flew the oblique-wing $A D-1$ aircraft to wing-skew angles of $60^{\circ}$ in cruise and landed at angles up to $45^{\circ}$. This unaugmented aircraft provided valuable information on the effects of cross coupling on handing qualities. Although skew effects are most dramatic during the first $45^{\circ}$ of skew angle, pilots found cross-coupling effects fairly minor in this regime. Between $45^{\circ}$ and $60^{\circ}$, however, the cross-coupling effects became significant in maneuvering flight. Windup turns to the left tended to steepen, while turns to the right were resisted because of changes in rolling moment due to angle of attack. Right rudder was required to coordinate both left and right turns. pilot ratings (Fig. 37) degraded by 2 to 3 numbers for wing-skew changes from $30^{\circ}$ to $60^{\circ}$. Simulation, using flight data, showed that rela-. tively straightforward control augmentation could dramatically improve flying qualities. The departure characteristics were also inferred from approaches to stalls.

Trim characteristics were examined, and pilots developed techniques and trim sequences for various wing-skew angles. A wing-pivot design approach to. improve static trim characteristics became apparent during this program.

Technology spinoff. One spinoff of this program was the refinement of parameter identification techniques for asymmetrical vehicles. These techniques had been developed using an RPRV model of an oblique-wing aircraft, but the $\mathrm{AD}-1$ flight test program provided the first opportunity to extract high-quality data in a wider flight regime for this class of vehicle. This test technique will be mandatory for any future asymmetrical vehicle. In addition, the program exposed a large number of pilots to a fairly radical wing configuration and demonstrated that, for large degrees of asymmetry, piloting techniques could be learned and applied quickly. Thus oblique-wing technology, which previously had been familiar to a relatively small segment of the industry, was introduced to a wide spectrum of the technical community.

Whereas wind tunnel data showed potential advantages of using an oblique wing in certain high-speed missions, the $A D-1$ validated the lowspeed part of the flight envelope in terms of handling qualities and dynamics. off-design characteristics were also explored in this program. The 
program was instrumental in securing support for studies and proposals for a more advanced research vehicle to explore the transonic and supersonic performance of an oblique-wing. configuration.

The AD-1 showed that the return on investment can be very high for small and inexpensive flight research vehicles. Although very limited in scope, such vehicles can address specific flight regimes, flight configurations, and flight dynamics issues, and provide a credible data base that includes data on pilot-vehicle interface as well as stability and control characteristics. The data from the AD-1 program represents the predominant source of flight data for skew-wing technology in the low-speed flight regime.

\section{Uncovering the Unexpected and Technology Payoff}

Research aircraft programs have always had specific objectives - either to validate performance or mission improvement predictions, or to explore unknown flight regimes. However, the unexpected still plays a major part in the total value of research aircraft programs. Two recent examples illustrate the kind of payoff that can result in the exploration of a technical area with a manned flight vehicle.

\section{Highly Augmented Aircraft Technology.}

The fifth air-launched test flight of the shuttle orbiter Enterprise at Edwards AFB uncovered a potential pilot-induced-oscillation (PIO) problem in the longitudinal axis of the vehicle (Fig. 38). This problem led several agencies to explore some of the fundamental problems of pilot-induced oscillations and to reexamine those issues related to overcontrol which have been seen in other highly augmented, digitally controlled flight vehicles. The research and development activity at AmesDryden involved a significant amount of research on both ground and in-flight simulators, the F-8 digital fly-by-wire aircraft, and a YF-12 aircraft being flown for other purposes. These experiments produced an improved understanding of the phenomena associated with pilot-induced oscillation and examined the validity of several criteria that had been proposed to help explain the effects of various parameters on pilot-induced oscillations.

Flight tests of the F-8 digital fly-by-wire aircraft showed the extreme effects of small amounts of added transport time delay in high-gain piloted tasks. This led to an increased understanding of time-delay effects and task criticality on pilot-induced oscillations.

The payoff of this serendipitous branch of the orbiter approach and landing test program included, first, improvements for the shuttle vehicle. In fact, a whole new class of nonlinear filters, called pro suppression filters (Fig. 39), were invented and are now an option for designers of future aircraft whose characteristics may induce similar piloted results.

Second, these studies and flight tests generated data and ideas for criteria for highly augmented aircraft, whose control systems dominate the stability and control response of the aircraft These vehicles are termed superaugmented aircraft.

Third, design guidelines have been developed for digital fly-by-wire prefilters and control laws to reduce the tendency for pilot-induced oscillations. Finally, a better understanding of simulation limitations in high pilot gain tasks was generated by this program in which close comparisons were made between the best ground-based and airborne simulations, and actual flight test. Thus the exploration of certain phenomena occurring in a flight program has, in this case, led to a broadened understanding of the interactions of the task, the pilot, and the vehicle systems, and has influenced both design approaches and design criteria.

\section{Integrated systems Technology.}

In another research aircraft program at AmesDryden, involving a high-performance cxuise aircraft, the inlet, autopilot, autothrottle, and air data system of an aircraft were integrated through a digital computer system to reduce the excursions in altitude at high cruise Mach number. The program objective was to reduce the pilot workioad and improve flightpath control in a very difficult task. The actual flight program validated these expectations by providing an improvement of approximately tenfold in flightpath control at high supersonic cruise.

What was not expected was a performance spinoff of this combined interactive and integrated propulsion flight control system. Improvements in range of approximately 7 percent resulted from many favorable interactions that occurred while attempting to reduce the flightpath excursions (Fig. 40). This has generated a new technology thrust for both supersonic and subsonic aircraft in providing design approaches for integrated flight and propulsion control systems, and has produced numerous ideas for integrated controls that exploit the interactions between many of these systems. Range improvement was not the objective of this program, and had not really been expected based on a substantial amount of analysis.

These two examples are not unusual in the world of flight research and testing. Many more exist and are well known within the technical community. The point is that, in addition to the primary objectives of a flight program, a substantial amount of technology benefit is incurred by attemptting to place an advanced idea or system into flight and making it work within the constraints of a manned aircraft operating in the real environment.

$\frac{\text { Generic Forces of the }}{\text { Research Alrcraft Program }}$

The examples of research aircraft programs discussed in this paper, as well as other such programs, demonstrate the generic forces that exist in research alrcraft programs that produce significant technoiogy output. The direct forces are those that are naturally present when an advanced technological concept or new configuration is applied in an actual filght vehicle and in the conduct of the research aircraft flight program. six distinct and highly significant forces can be derived based 
on the history of research aircraft programs (Table 5). The research aircraft flight program:

\section{Separates real from imagined problems.}

Research aircraft flight programs tend to expose the real problems, whereas the severity of a technological barrier is not always clear in the analytic regime. Often the only way to confront such problems is to carry the concept to the flight regime. Analytic or ground test data cannot include ali models of the actual dynamic filght environment, thus requiring uncertainty levels to be applied to key results and predictions. This applies to aerodynamic, performance, propulsion, systems, and flying qualities characteristics. Thus potential, or "imagined," problems are held to be possible technical barriers. As flight programs are formulated, of ten requiring large financial resources, natural forces quickly sort real and imagined problems. Because serious problems of ten suspend or halt flight programs, solutions are forced as need becomes the mother of invention. This dictum, first concisely stated by Hugh L. Dryden, has been borne out repeatedly in research aircraft programs.

2. Uncovers the unexpected and overlooked.

Another dictum by Dr. Dryden continues to be upheld in most flight programs. As previous examples have shown, flight research programs can reveal surprises, both good and bad. Often the surprises are not in the main experiment but in the supporting technologies that are necessary to accomplish the main experiment. The issues are often found to be generic, such as the inability to make measurements suitable for validating the performance of a particular technology or problems in actually achieving the predicted performance, or the effectiveness of a given system. In any case, no flight research program is without major surprises.

In this category are included unexpected coupling between advanced control laws and pilot technique which have caused structural design limit loads to be exceeded in one case, and serious pilot-induced oscillations in another case. These kinds of valuable serendipitous results should be distinguished from those surprises that result from poor or inadequate preflight analyses. Of course, poor predictions usually lead to surprising flight results.

In the Ames-Dryden experience of conducting research and experimental aircraft programs, these valid unexpected results often form a basis for more focused research in key areas and provide valuable feedback to the designer, by surfacing shortcomings in the design tools, environment models, or interaction models. They have often rivaled in importance the main objectives of a flight program.

\section{Forces realistic integration of the pilot.}

The pilot-vehicle interface is often difficult to predict in the analytical phase of the development of an advanced aerodynamic; structural, propulsion, or control concept. In a research aircraft implementation, however, the designer is forced to deal with flying qualities, man-machine factors, and physiological factors. The apparent benefits of rolling an aircraft about the stability axis during high-angle-of-attack flight is an interesting example of this. In one program at Ames-Dryden this maneuver was performed using onboard control mechanization, which was found to provide good vehicle dynamies but unusual motion cue effects, which the pilot found to be unpleasant and distracting. The proper mixture of displays, training, and control necessary for a pilot to exploit some of these dynamics during high-angleof-attack flight is not yet clear.

Even systems designed by pilots in highfidelity simulators are often found to be "losers" when mechanized in actual flight vehicles. For example, in several cases caution and warning displays have been optimized on a simulator and later abandoned in flight because of their complexity and inability to display quickly and concisely the information that the pilot really needs. Another surprising man-machine effect occurred in an aircraft experiment using an advanced digitally controlled engine. Changes made to the dynamics of the engine to improve performance resulted in serious deficiencies in flying qualities during formation flight. This led to the investigation of the man-machine interface with engines that are heavily augmented with digital controls. As a result, design criteria for acceptable engine "flying qualities" are being developed.

\section{Forces development of credible prediction, test, and qualification processes.}

The development of a research aircraft requires sufficient testing and qualification to assure safety of flight. The processes required to design and qualify the research aircraft for flight are often no different than those required for operationa 1 application of these new technologies. Use of a manned research aircraft establishes the real verification and validation burden. For example, the immense software verification and validation burden for a full-authority digital fly-by-wire aircraft control system was not identified in publications prior to 1970. Research aircraft programs using these.kinds of systems quickly established the need for more systematic processes and standards, so that the manufacturer, the customer, the certifying or qualifying agency, and the pilot could agree that the aircraft and its advanced systems were ready for flight.

Because of the life criticality of some flight conditions, research aircraft programs of ten mature the development of predictive tools in a manner rarely observed otherwise. For example, in recent years, aeroservoelasticity predictive methods for digital fly-by-wire-controlled, highly elastic aircraft have been advanced to an extremely credible and accurate state because of the demands for such analyses prior to prototype or experimental fight test.

In some cases, the flight research process forces development of new tools and methods which then become the standard for subsequent applications of these technologies. At Ames-Dryden, a new class of specialized ground support equipment was developed 18 to conduct integrated testing, verification, and validation of flight-crucial digital systems 
because of the need to qualify such systems for Elight. Research aircraft have also generated the need for new flight test techniques and methods that have been used on a wide variety of aircraft following their initial experimental application. For example, methods were developed to extract aerodynamic stability and control derivatives from flight maneuvers. This approach has subsequently been found useful in a wide variety of aviation applications.

\section{Requires every anomaly to be addressed.}

In any research flight vehicle, either the cost, visibility, or life criticality forces a serious, intensive, and systematic approach to addressing anomalies or problems that occur. Anomalies that occur in a flight test program require in-depth analysis and understanding of the sources of such anomalies. This invariably leads to an improved understanding of the technology, the systems, and the factors contributing to the anomalous operation or anomalous flight results. In conducting both laboratory and flight experiments, the attitudes of the research scientist and engineer vary because of the impact of the anomaly, the experimental objectives, and the available resources. In any flight program, every anomaly must be addressed and explained to the satisfaction of the testing organization and the pilot. This is rarely the case for purely experimental laboratory systems or analytic results.

6. Forces timely technology transfer and builds core technical team.

Research aircraft programs are generally conducted by joint Government-industry teams. Technology transfer is simultaneous with data acquisition and analysis, and occurs continuously during the definition, development, and flight phases of the program. Feedback to the design process is timely if designers remain associated with the flight program.

The resulting Government technical team often becomes a repository of data and experience that can be applied in subsequent advanced aircraft development. Government expertise is important in aiding industry in conducting advanced tests and in conducting basic research in key technical areas. Government involvement in flight research also ensures that flight results are widely disseminated, and that results from various programs are compared, sifted, sorted, and placed in a National data base.

Even more significant, and perhaps ultimately the major contribution of flight research programs is the transfer of technology that usually results from these programs. When concepts and ideas, which may lie unnoticed and unappreciated for years, survive serious scientific attention, analysis, and testing in the flight regime by designer, developer, and pilot, they become immediate options and candidates for technology application. This is the bottom line in the value of flight research programs, acting as a direct force or catalyst in achieving better aircraft.
Aeronautical Technology Application Trends

It is instructive to examine fixed-wing technology application trends in the U.S. over the past 40. years. Figures 41 and 42 summarize this flow. for both aerodynamic and systems concepts. The figures show qualitatively the historical relationship between technology advances in the various fixed-wing airplane classes. Several points are evident.

1. Research aircraft have contributed significantly to technology found today on vehicles of all classes.

2. There is generally a long gestation time between concept exploration and ultimate operational introduction.

3. There is an unaistakable technology flow from high-performance aircraft to subsonic and transport aircraft.

4. There is a strong technology flow from military to civil ajrcraft.

5. In recent years, general aviation has moved aggressively to incorporate advanced technology, occasionally before Government flight research programs.

\section{Looking Ahead: Research Aircraft of the Future}

Whereas in the past, many research aircraft were intended to look at only one aspect of the technology, research aircraft currently being developed by Government/industry teams tend to involve multiple technologies: In the case of the HiMAT program, the research aircraft itself was designed to investigate the interaction and deliberate exploitation of the interaction of several aerodynamic, structural, propulsion, and electronic technologies.

Looking to the future, several new research aircraft are about to begin their flight program lives at the Ames-Dryden Flight Research Facility.

The AFTI/F-111 mission adaptive wing program will explore smooth variable camber and advanced digital flight control to achieve optimum performance and capability throughout the flight regime (Fig. 43). Automatic performance-seeking modes will attempt to maximize the performance parameter through an on-line real-time control approach that will couple the digital flight control and the advanced wing to produce either an optimum cruise configuration or an optimum maneuvering configuration. This program will produce a rich data base for adaptive wing configurations, which have a variety of applications. The benefits and penalties of the internally actuated smooth variablecamber configuration will also be revealed.

The F-15 highly integrated digital electronic control (HIDEC) program (Fig. 44) will explore the use of highly integrated flight and propulsion control systems. Close coupling of the aircraft flight control system and digital engine control system will allow the engine stall margin to be 
continuously varied to improve performance and mission capability.

The $x-29$ forward-swept wing aircraft, which is a joint project of the Defense Advanced Research Projects Agency (DARPA), Grumman, the U.S. Air Force, and NASA (Fig. 45), will begin where the HiMAT airplane left off in combining an advanced forward-swept wing; a close-coupled allmoving canard; variable camber in double-hinged trailing-edge flaps; three-surface control involving the canard, the trailing-edge flaps, and a strake flap; the use of large negative static margin; an advanced digital fly-by-wire control system; and an aeroelastically tailored wing. The $x-29$ program is expected to produce a wealth of data related to advanced fighter design in all these technologies as well as in the exploration of the interaction of these technologies in a real aircraft.

The potential problems of the coupled aeroelastic modes of the wing and the high-gain control system have produced new challenges in an effect called aeroservoelasticity. Already this program has forced the maturing of very advanced analysis and design codes because of the critical nature of these problems for the success of the $x-29$ aircraft. This also represents an indirect force of the flight program itself. In addition, the high degree of longitudinal negative static margin has forced in-depth research into the nature of flight control capabilities in providing the necessary stability and control of such aircraft, which represents a technology spinoff before the aircraft is even flown.

Looking further ahead, in an extremely ambitious program, the $\mathrm{x}$-wing aircraft (Fig. 46) is meant to explore advanced composite structures, aeropneumodynamics, circulation control, and a very complex flight control system to accomplish combinations of horizontal and powered lift flight that have not been attempted heretofore. The mere undertaking of many of these problems is producing technology advances in aspects of flight control, structural design, and rotorcraft dynamics.

In the latest proposal for a new research aircraft, NASA Ames is conducting preliminary studies for a manned, full-scale transonic oblique-wing experiment that would place an oblique wing on the F-8 digital fly-by-wire aircraft (Fig. 47). This research aircraft program is being formulated to provide flight data for correlation with wind tunnel results and transonic computational codes. The program would also produce a usable and credible data base for application of oblique-wing technology to a variety of aircraft missions. The experimental approach is to design an oblique wing to produce both research data and a realistic maneuvering wing configuration applicable for DOD missions. In this sense, the objectives of the program would force designers to examine the interaction of the aerodynamic, structural, control system, and flying qualities disciplines to achieve both cruise and maneuver performance within practical weight constraints. In addition, this program would force close examination of the various trades between subsonic and supersonic performance in the real flight environment. Handling qualities studies of the vehicle for both unaugmented and augmented configurations are expected to provide new criteria for asymmetrical vehicles. Another important element of this program is the close cooperation that is planned between industry and Government, involving both NASA and DOD, to provide timely technology transfer.

The NASA approach in this program is also to exercise, to the greatest degree possible, the industry and Government prediction methods, design tools, and expertise during the early phases of the program such that these predictive methods can be continuously updated throughout the program. Cost being an important factor in any new resarch program, this program approach depends on utilization of the existing F-8 aircraft and its capable faulttolerant digital fly-by-wire control system. of course, new control algorithms must be developed to accommodate the asymmetrical vehicle. This program was prompted by the predicted performance benefits of the oblique-wing concept. It is expected that the program will demonstrate the levels of performance that can be achieved with this technology, as well as the technical barriers to its application. It is also expected that interactive aerodynamics. structures, and controls technology will be advanced as the design is undertaken for the real flight environment. This program would follow the model of many successful flight research programs.

\section{Concluding Remarks}

Research aircraft have been associated with each of the various phases of research itself, from fundamental studies to full-scale systers experiments. Too of ten, flight research is erroneously thought of as being the final step in the aeronautical research process.

Research aircraft serve to bring new technology to the flight environment to discover the actual performance benefits and the actual penalties and burdens which may accompany any new technology. This role of the research aircraft has probably been the most significant throughout the years. Those research aircraft that represent new classes of vehicles, such as lifting bodies, or vehicles such as the HiMAT or $x-29$, represent the extreme end of the spectrum, in which several technologies are advanced at once to prove and evaluate the performance benefits and burdens that result from their interaction. These kinds of flight programs represent the most costly ones but also represent the greatest opportunity to advance whole technological fields and produce a high return on investment by bringing to bear the best skills, tools, and ideas of industry and Government in an actual new flight aircraft configuration that may be the forerunner of a new class of aircraft.

Flight demonstration is occasionally criticized as a fly-for-show experience in which nc new technology is generated, but in which the flight activity is undertaken only to prove to some segment of industry or Government that technology is actually in hand. In reality, very few, if any, flight research programs have begun with this objective. In many cases, however, the flight programs have sufficently matured a technology as to prove it to be viable for near-term application. This is a payoff and spinoff of a well conducted research program and generally not the primary objective. 
Actually, demonstration of technology for application occurs in prototype aircraft.

The benefits of a research aircraft program can then be summarized as follows:

1. To measure and observe the performance or mission improvement benefits of a technology in the real flight world involving the aircraft, its environment, and the man.

2. To mature the design capability by exposing the design process to the real environment and by being forced to conduct detalied analysis of anomalous or of $f$-design performance capability.

3. To involve industry and Government in partnership, thereby bringing together inventors, suppliers, and users of the technology.

4. To expose the real problems or technology barriers that need to be addressed in more basic research programs.

5. To mature supporting technologies, including design tools, test tools, test methods, and qualification methods.

6. To focus fundamental research in the flight environment on problems that have not been able to be solved by other means.

7. To involve the man, the ultimate user of the aircraft, who provides both the subjective and objective assessment of the total worth and value of an aircraft system or technology in its application to the mission.

The future of research aircraft is exciting because one can look forward to the development of research aircraft in the hypersonic and transatmoshperic vehicle classes. Such aircraft are virtua 11 y guaranteed to press the technology faster than any other method known, and to provide a wealth of spinoff technology as history has shown such programs do.

\section{References}

Ispearman, M. L., "Historical Development of Worla Wide supersonic Aircraft," AIAA Paper 79-1815, AIAA Aircraft systems and Technology Mtg., New York, N.Y., Aug. 20-22, 1979.

2 Anderson, S. B. and Nelms, W. P., "VSTOL Concepts in the United States' Past, Present, and Euture," NASA TM-85938, 1984.

${ }^{3}$ Whitcomb, Richard T., "Review of NASA Supercritical Airfoils," ICAS Paper 74-10, The Ninth Congress of the International Council of the Aeronautical Sciences, Haifa, Israel, Aug. 25-30, 1974.

4 "Description and Flight Test Results of the NASA F-8 Digital Fly-By-Wire Control system," NASA TN D-7843, 19.75.

${ }^{5}$ Szalai, K. J., Felleman, P, G., Gera, J., and Glover, R. D., "Design and Test Experience with a
Triply Redundant Digital Fly-by-wire Control Sys tem," AIAA Paper 76-1911, AIAA Guidance and Control Conf., San Diego, Calif., Aug. 16-18, 1976.

${ }^{6}$ szalai, Kenneth J., Jarvis, Calvin R., Krier, Gary E., Megna, Vincent A., Brock, Larry D., and O'Donnell, Robert N., "Digital Fly-By-Wire Flight Control Validation Experience," NASA TM-72860, 1978.

${ }^{7}$ Brock, L. D. and Goodman, H. A., "Reliability Analysis of the F-8 Digital Fly-By-Wire System," NASA CR-163110, 1981 .

${ }^{8}$ Deckert, James C. and Szalai, Kenneth J., "Analytic Redundancy Management for Flight Control Sensors," Advances in Sensors and Their Integration Into Aircraft Guidance and Control Systems, AGARDograph No. 272, June 1983, pp. 9-1 to $9-13$.

${ }^{9}$ Shafer, Mary F., Smith, Rogers E., Stewart, James F., and Bailey, Randall E., "Flight. Test Experience with Pilot-Induced-Oscillation Suppression Filters," NASA TM-86028, 1984.

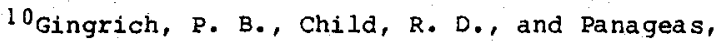
G. N., "Aerodynamic Configuration Development of the Highly Maneuverable Aircraft Technology Remotely Piloted Research Vehicle," NASA CR-143841, 1977.

1l Arnaiz, Henry H. and Loschke, Paul C., "Current Overview of the Joint NASA/USAF HiMAT program," Tactical Aircraft Research Technology, NASA CP-2162, Part 1, 1980, pp. 91-121.

12 Matheny, Neil W, and Panageas, George N. , "HimaT Aerodynamic Design and Flight Test Experience," AIAA Paper 81-2433, AIAA Flight Testing Conf., Ias Vegas, Nev., Nov. 11-13, 1981.

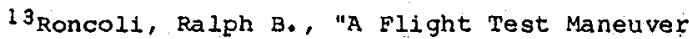
Autopilot for a Highly Maneuverable Aircraft." NASA TM-81372, 1982 .

${ }^{14}$ Duke, E. L. and Lux, D. P., "The Application and Results of a New Flight Test Technique," AIAA Paper 83-2137, AIAA Atmospheric Flight lechanics Conf., Gatlinburg, Tenn., Aug. 15-17, 1983.

15 Anđrews, W. H., Sim, A. G., Monaghan, R. C., Felt, L. R., McMurtry, T. C., and Smith, R. C., "AD-1 Oblique Wing Aircraft Program," SAE Technical Paper 801180, Aerospace Congress \& Exposition, Los Angeles, Calif., Oct. 13-16, 1980.

16McMurtry, T. C., Sim, A. G., and Andrews, w. H., "AD-1 Oblique Wing Aircraft Program," AIAA Paper 81-2354, AIAA/SETP/SFTE/SAE/ITEA/IEEE ist Flight Testing Conf., Las Vegas, Nev., Nov. 11-13, 1981.

${ }^{17}$ Curry, R. E, and Sim, A. G., "Unique Flight Characteristics of the $A D-1$ Oblique-Wing Research Airplane," J. Aircraft, vol. 20, no. 6, June 1983, pp. 564-568.

18 Glover, Richard D., "Aircraft Interrogation and Display System: A Ground Support Equipment for Digital Elight Systems," NASA TM-81370, 1982. 
Table 1 Expansion of manned flight envelope by $x$-series aircraft

\begin{tabular}{|c|c|c|c|}
\hline Aircraft & Event & Date & Pilot \\
\hline$x-1$ & $\mathrm{Mach} 1.06$ & October 14,1947 & Yeager \\
\hline$x-1$ & Mach 1.45 & March 26, 1948 & Yeager \\
\hline $\begin{array}{l}\text { D558-II } \\
\text { D558-II }\end{array}$ & $\begin{array}{l}\text { Mach } 1.87 \\
\text { Mach } 2.005\end{array}$ & $\begin{array}{l}\text { August } 7,1951 \\
\text { November } 20,1953\end{array}$ & $\begin{array}{l}\text { Bridgeman } \\
\text { Crossfield }\end{array}$ \\
\hline$x-1 A$ & $\begin{array}{r}\text { Mach } 2.435 \\
74,200 f t\end{array}$ & December 12,1953 & Yeager \\
\hline$x-1 A$ & $90,443 \mathrm{tt}$ & August 26,1954 & Murray \\
\hline$x-2$ & $\operatorname{Mach} 2.87$ & July 23, 1956 & Everest \\
\hline$x-2$ & $126,200 \mathrm{ft}$ & Septenber 7, 1956 & Kincheloe \\
\hline $\begin{array}{l}x-2 \\
x-15\end{array}$ & $\begin{array}{l}\operatorname{Mach} 3.2 \\
354,200^{2} \mathrm{ft}\end{array}$ & $\begin{array}{l}\text { September } 27,1956 \\
\text { August } 22,1963\end{array}$ & $\begin{array}{l}\text { Apt } \\
\text { Walker }\end{array}$ \\
\hline$x-15$ & $\operatorname{Mach} 6.7$ & October 3, 1967 & knight \\
\hline
\end{tabular}

Table 2 Assessment of research data for HiMAT vehicle

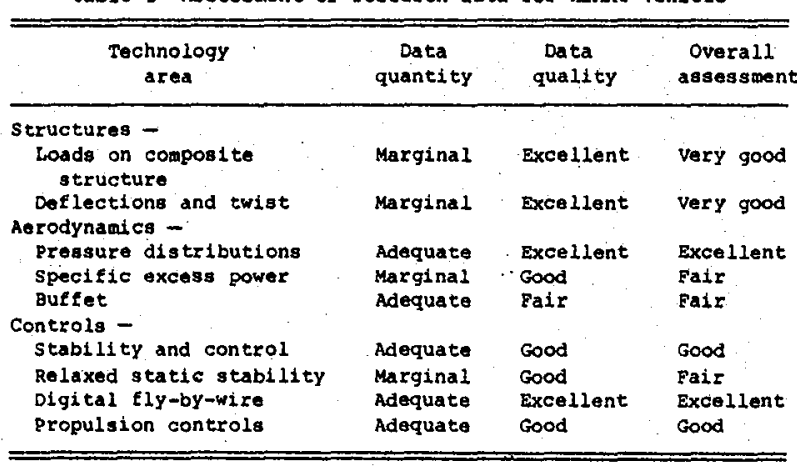

Table 3 Functions of HiMAT airborne computer system

\begin{tabular}{|c|c|}
\hline Function & Computational rate, $\mathrm{Hz}$ \\
\hline $\begin{array}{l}\text { Primary Computer } \\
\text { adrcraft control by primary } \\
\text { control systen } \\
\text { Uplink processing } \\
\text { Downlink processing } \\
\text { Failure management } \\
\text { backup propulsion control } \\
\text { Interrupt processing } \\
\text { Mdscellaneous functions } \\
\text { Backup Computer } \\
\text { CAircraft control by backup } \\
\text { control system } \\
\text { Uplink processing (discrete) } \\
\text { Failure management } \\
\text { Integrated propulsion control } \\
\text { Interrupt processing } \\
\text { Miscellaneous functions. }\end{array}$ & $\begin{array}{l}53.3 \\
106.6 \\
220,55 \\
55,53,3,50,25,10,1 \\
50 \\
2420,106.6,100,75 \\
50,25,10 \\
100,50,10 \\
50, \\
50,10,1 \\
33.3 \\
105.6,100 \\
50,10\end{array}$ \\
\hline
\end{tabular}

rable 4 Physical characteristics of AD-1 alrplane

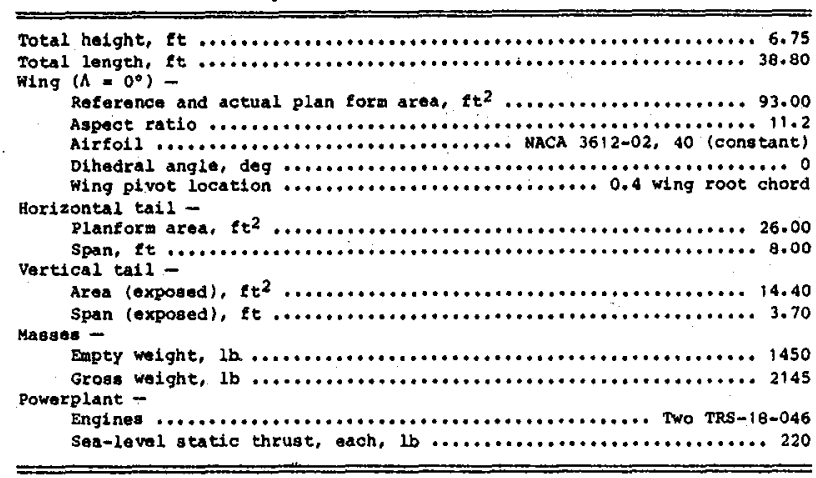

Table 5 Forces of the Elight progran

\begin{tabular}{|c|c|}
\hline Item & Impact \\
\hline $\begin{array}{l}\text { Separates real from } \\
\text { imagined problems }\end{array}$ & $\begin{array}{l}\text { Exposes real problems } \\
\text { Forces solutions } \\
\text { Provides feedback to designer }\end{array}$ \\
\hline $\begin{array}{l}\text { Uncovers the unexpected } \\
\text { and overlooked }\end{array}$ & $\begin{array}{l}\text { Reveals surprises, bad and good } \\
\text { Shows generic issues }\end{array}$ \\
\hline $\begin{array}{l}\text { Forces realistic integration } \\
\text { of the pilot }\end{array}$ & $\begin{array}{l}\text { Handling qualities } \\
\text { Man-machine factors } \\
\text { Physiological factors }\end{array}$ \\
\hline $\begin{array}{l}\text { Forces development of } \\
\text { credible prediction, test, } \\
\text { and qualification } \\
\text { processes }\end{array}$ & $\begin{array}{l}\text { Establishes real verification and } \\
\text { validation burden } \\
\text { Forces development of new tools } \\
\text { and methods }\end{array}$ \\
\hline $\begin{array}{l}\text { Requires every anomaly } \\
\text { to be addressed }\end{array}$ & $\begin{array}{l}\text { Forces in-depth understanding of } \\
\text { system concepts } \\
\text { oftan leads to design concepts. }\end{array}$ \\
\hline $\begin{array}{l}\text { Forces timely technology } \\
\text { transfer and builds core } \\
\text { technical team }\end{array}$ & $\begin{array}{l}\text { Provides technology transfer } \\
\text { concurrent with vehicle design } \\
\text { Builds lasting technical team } \\
\text { capability }\end{array}$ \\
\hline
\end{tabular}




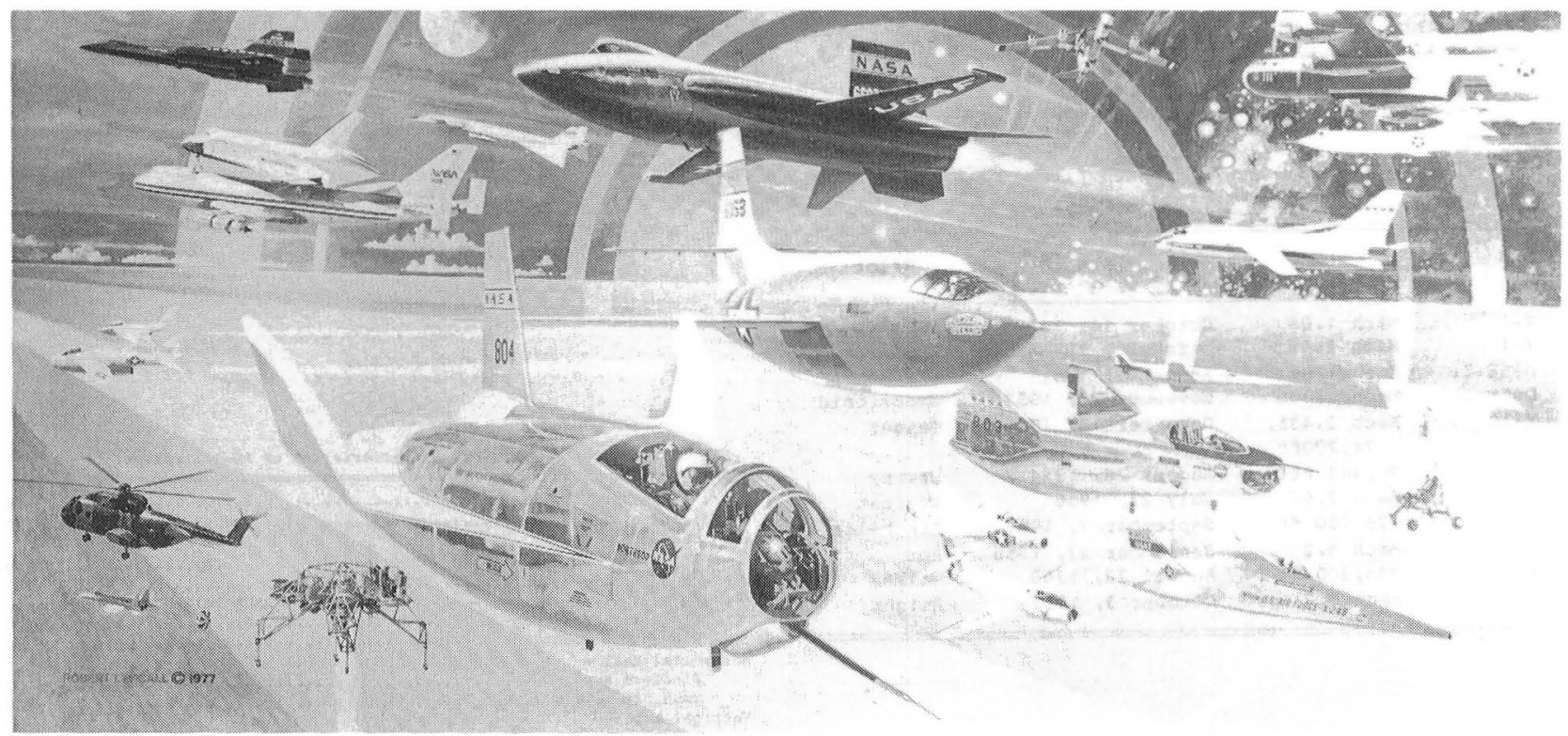

Fig. I Research aircraft flown at Ames-Dryden.
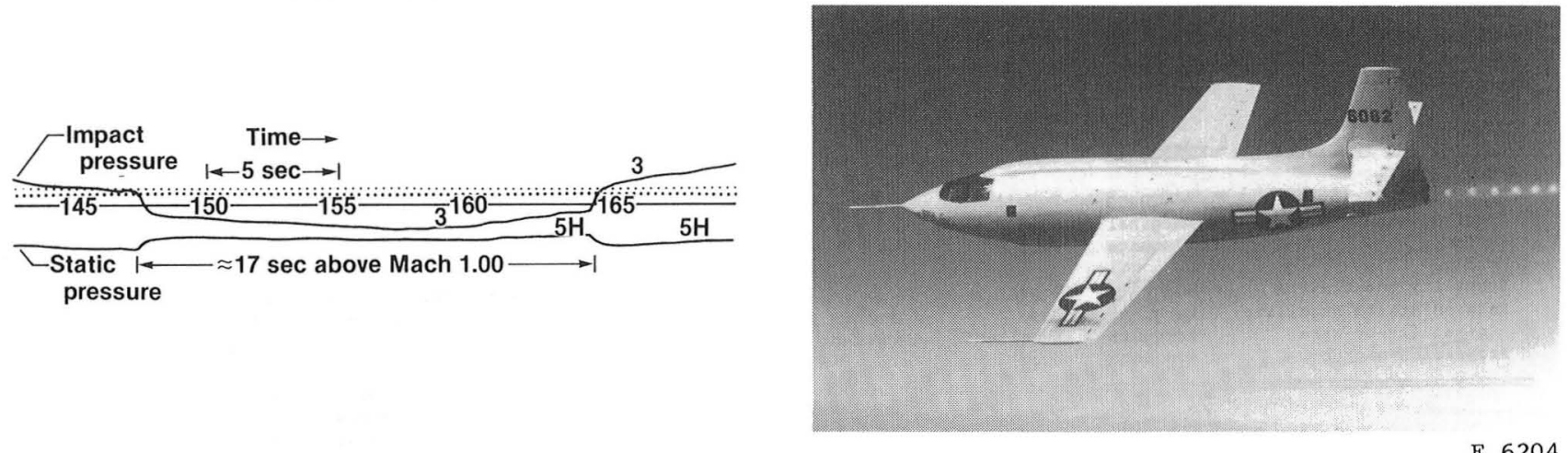

Fig. $2 x S-1(x-1$ No. 1) in powered flight and historic first recorded Mach jump, Oct. 14, 1947.

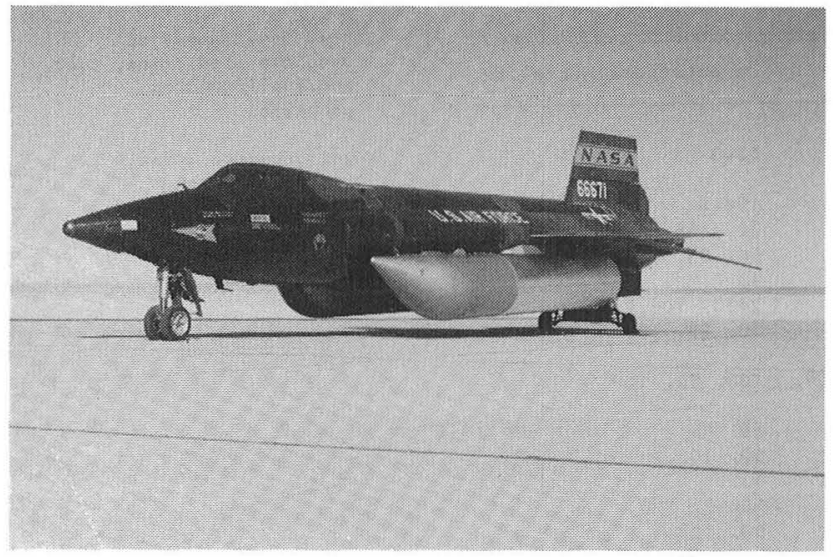

ECN 897

Fig. $3 \quad x-15$ aircraft. 


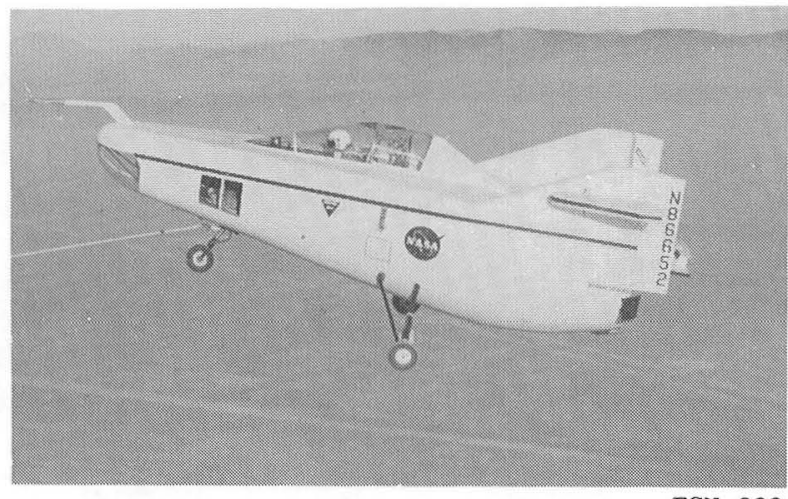

ECN 229

(a) Lightweight M2.

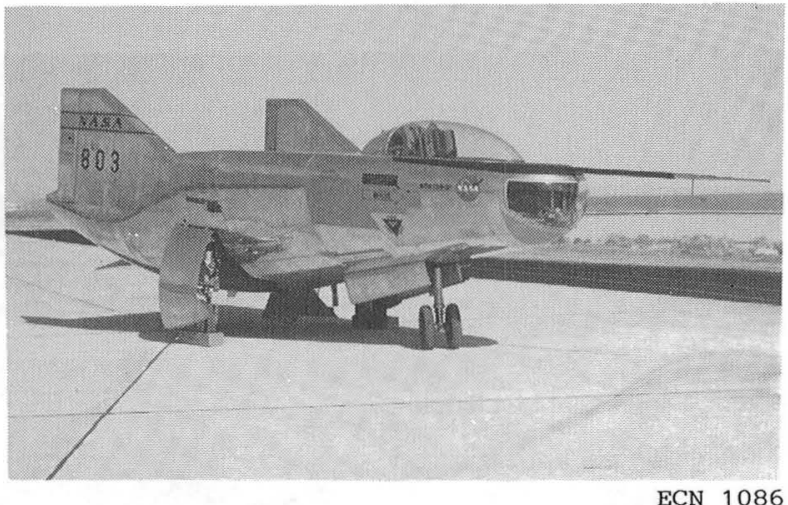

(b) $M 2-F 2$.

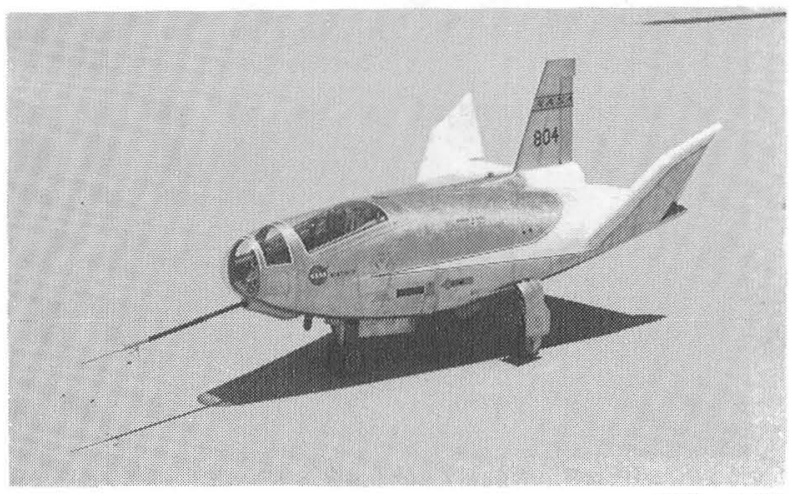

ECN 2064

(C) $H L-10$.

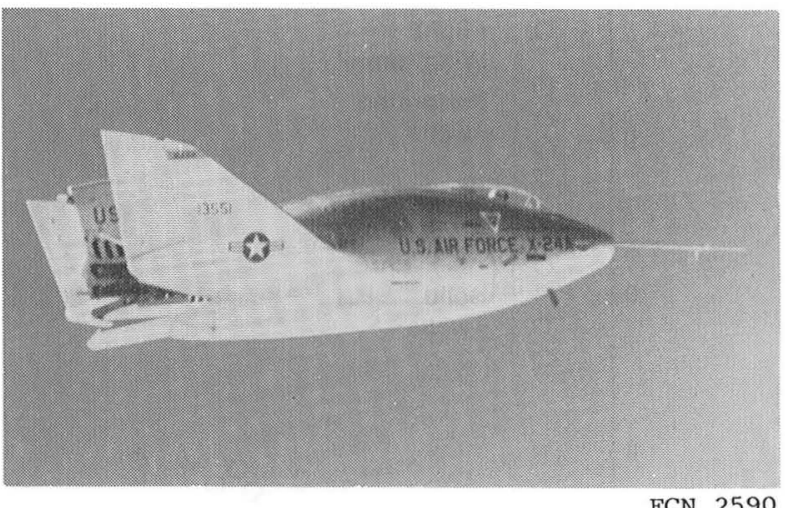

(d) $X-24 A$.

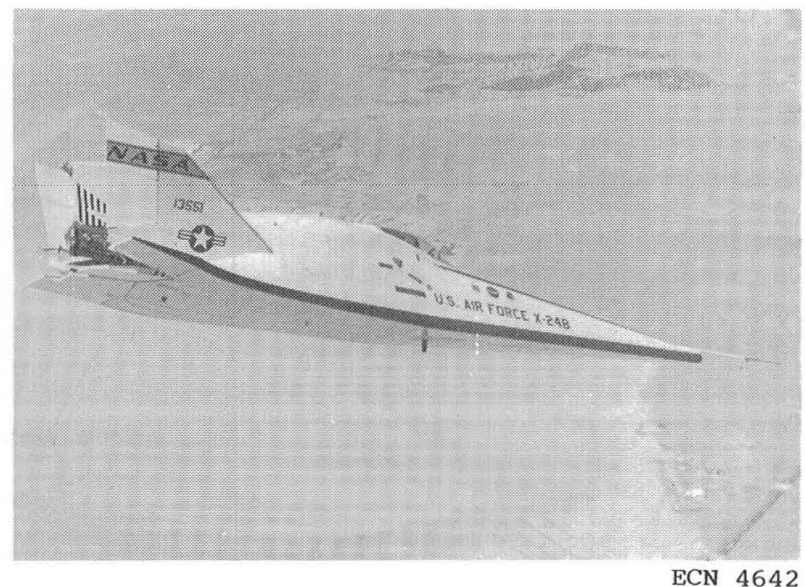

Fig. $5 x-24 B$ modified lifting body. 


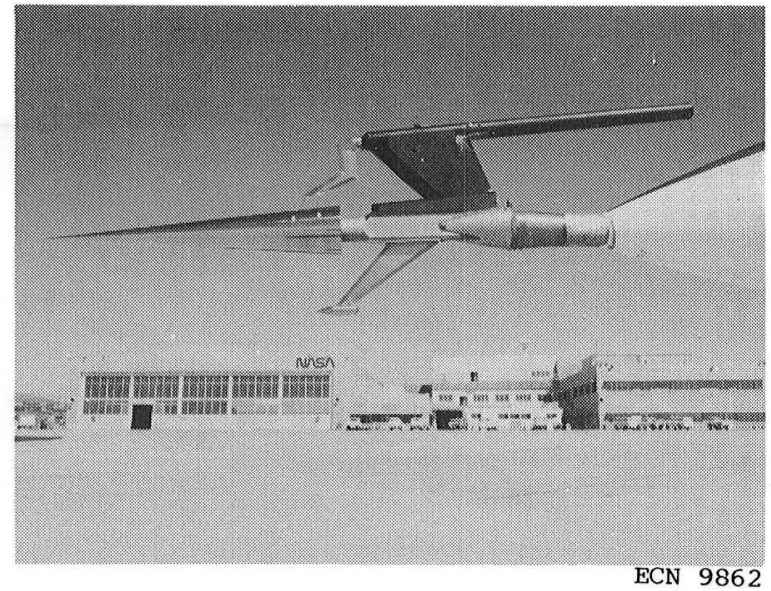

(a) $10^{\circ}$ cone installation on F-15 aircraft.

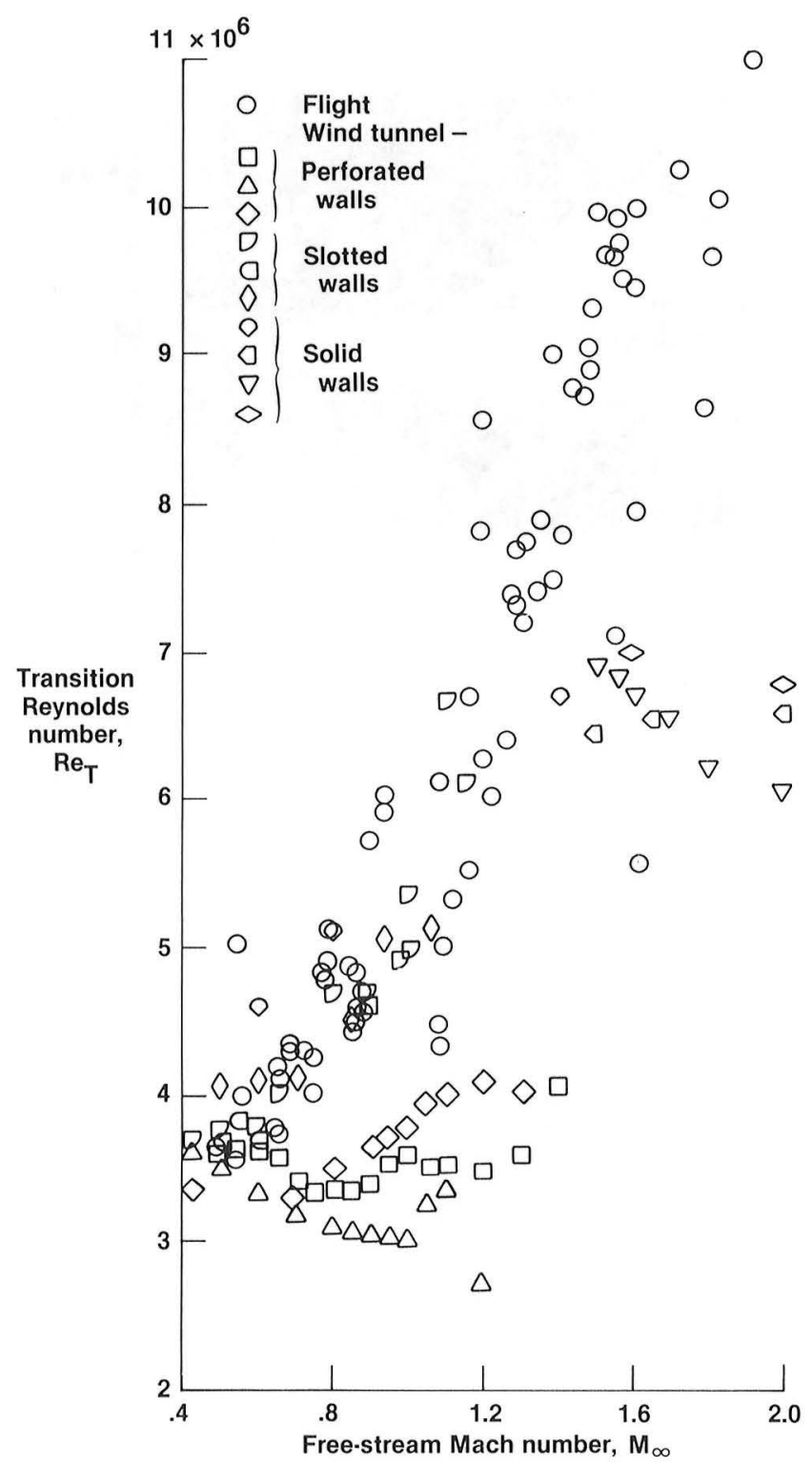

(b) Comparison of wind tunnel and flight data.

Fig. $6 \quad F-1510^{\circ}$ cone transition Reynolds number flight experiment.

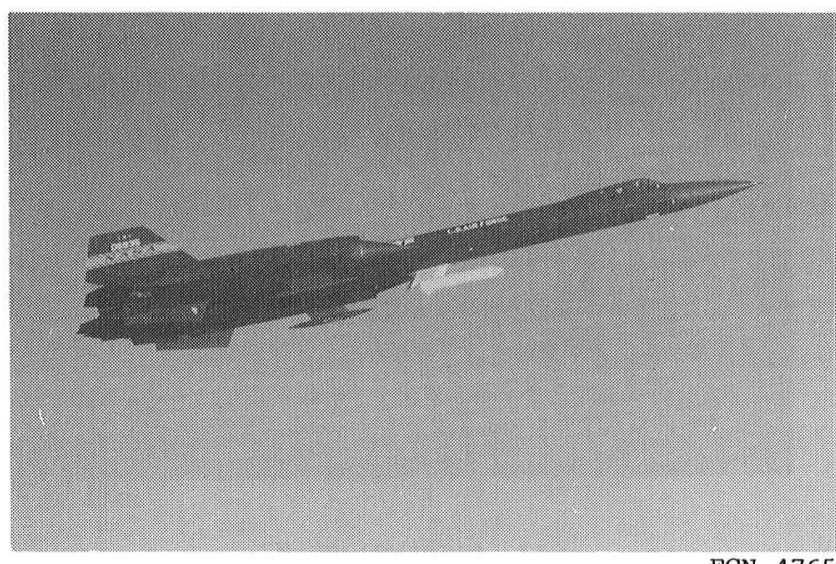

ECN 4765

Fig. 7 YF-12 aircraft with cold-wall experiment.

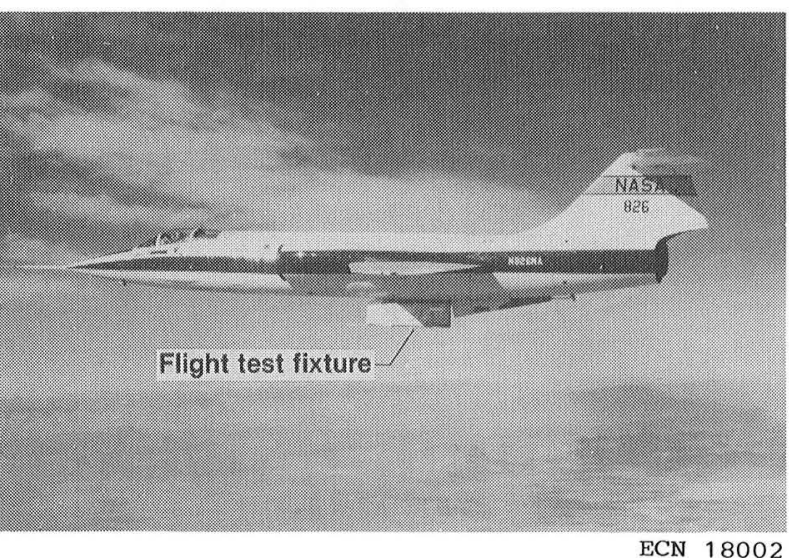

Fig. 8 Flight test fixture installed on lower fuselage of $F-104$ carrier aircraft.

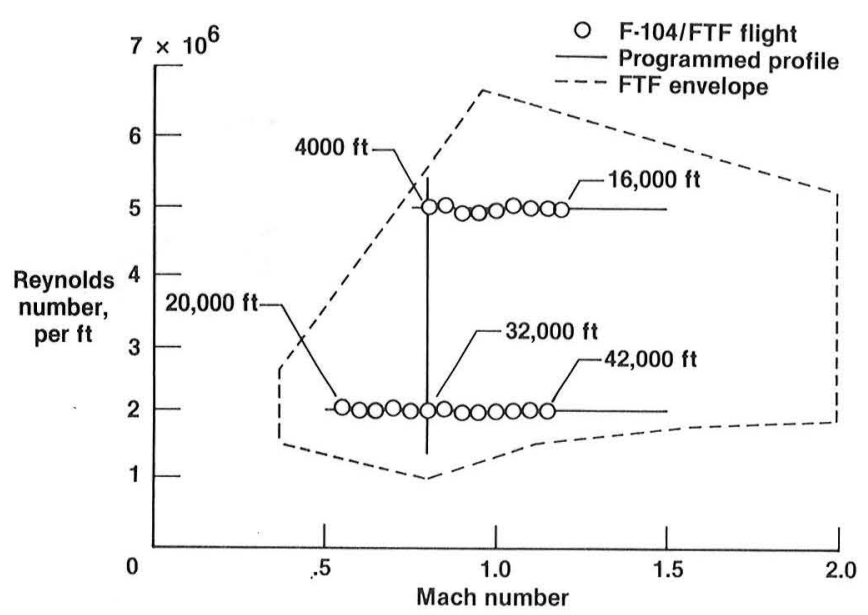

Fig. 9 Flight test fixture (FTF) test envelope, and typical Reynolds number versus Mach number trajectories. 


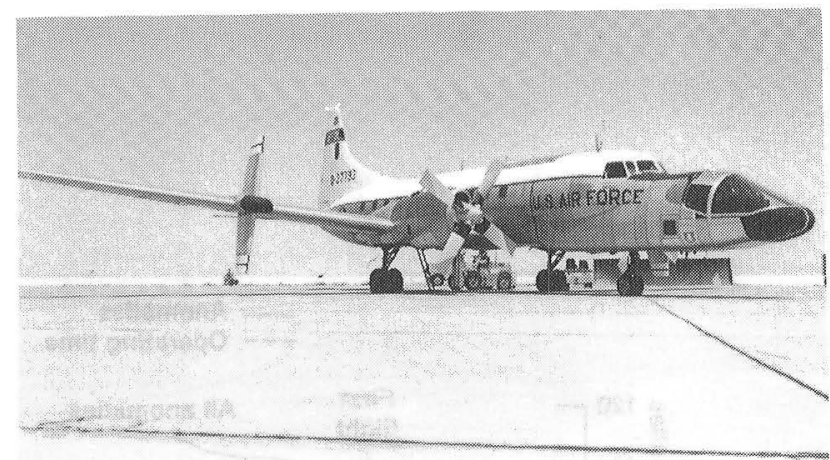

ECN 29514

Fig. 10 Calspan TIFS aircraft.

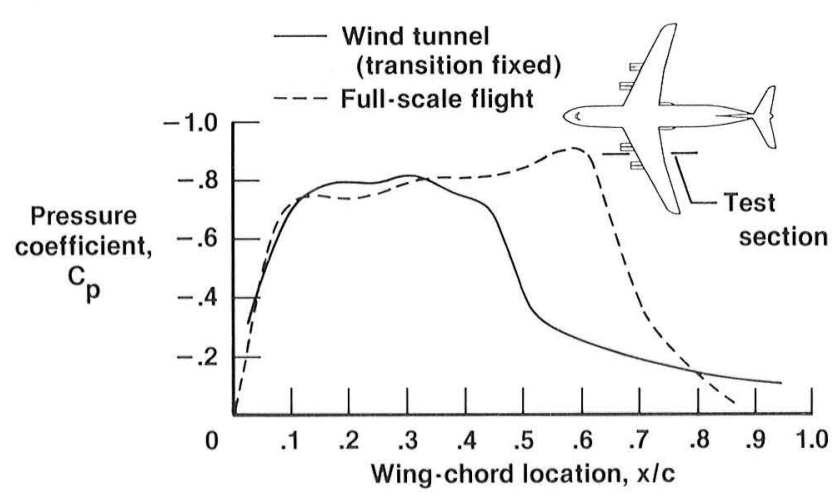

Fig. 11. Shock wave discrepancy at transonic speeds.

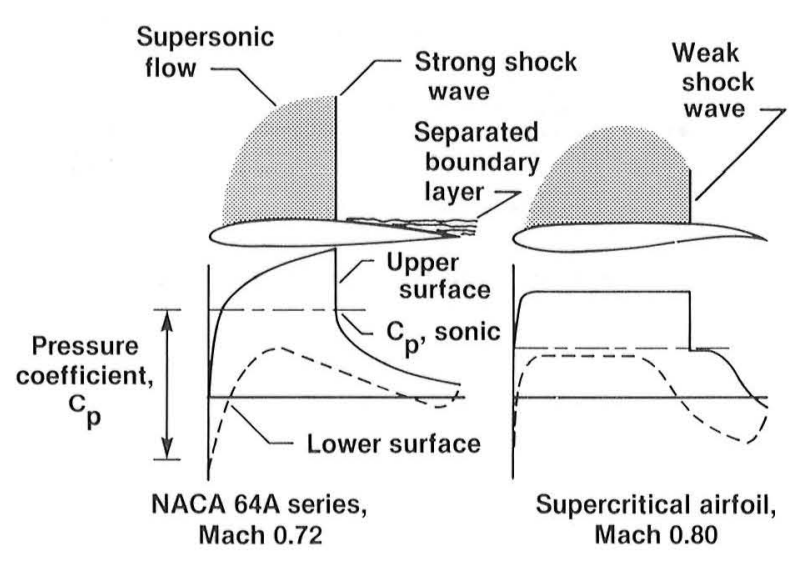

Fig. 12. Supercritical wing airfoil design.

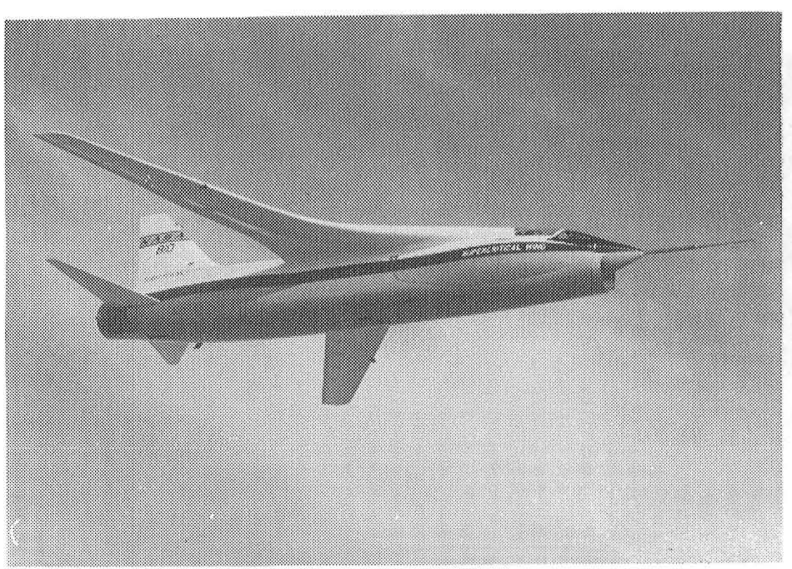

ECN 3468

Fig. 13 F-8 supercritical wing aircraft in flight.

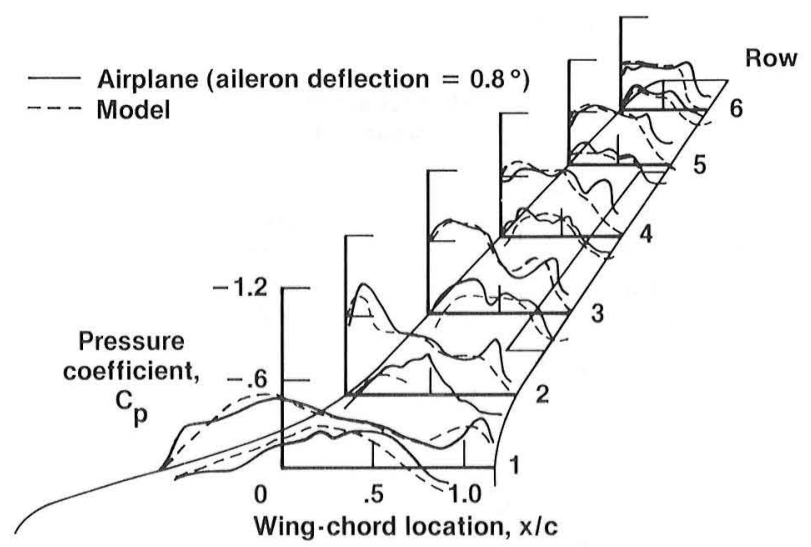

Fig. 14. Wind tunnel and flight pressure distributions for supercritical wing.

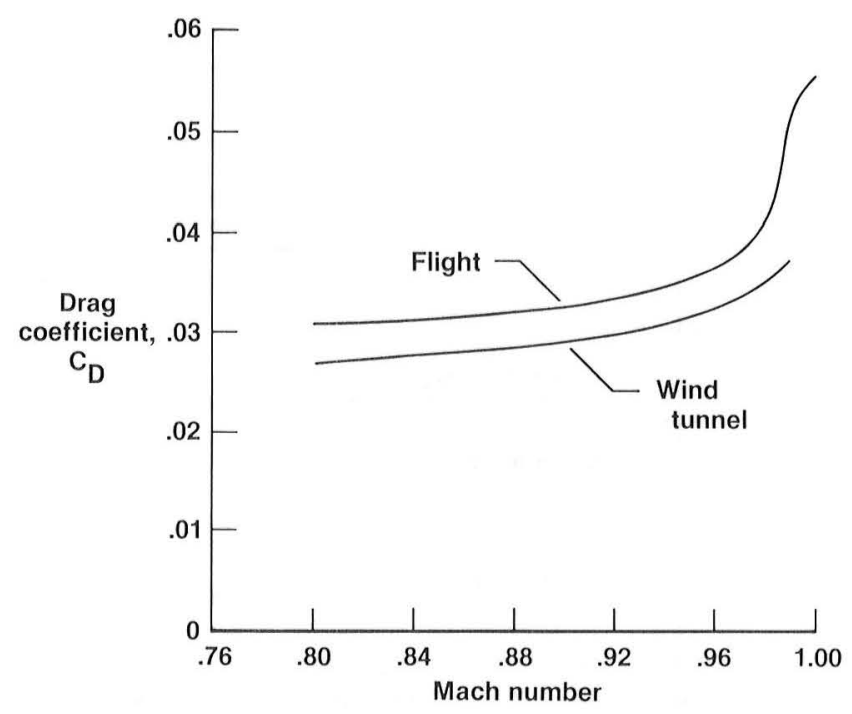

Fig. 15. Wind tunnel and flight drag coefficients for supercritical wing. 


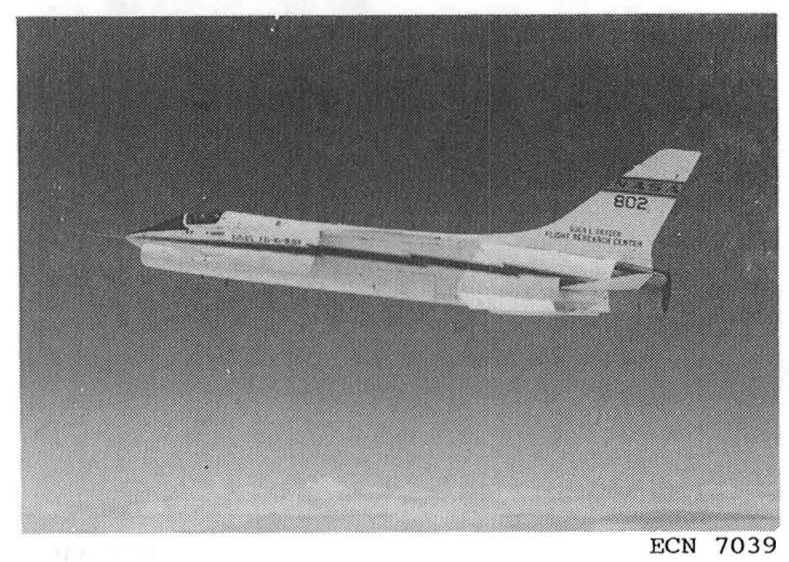

Fig. $16 \quad$ F-8 DFBW aircraft.

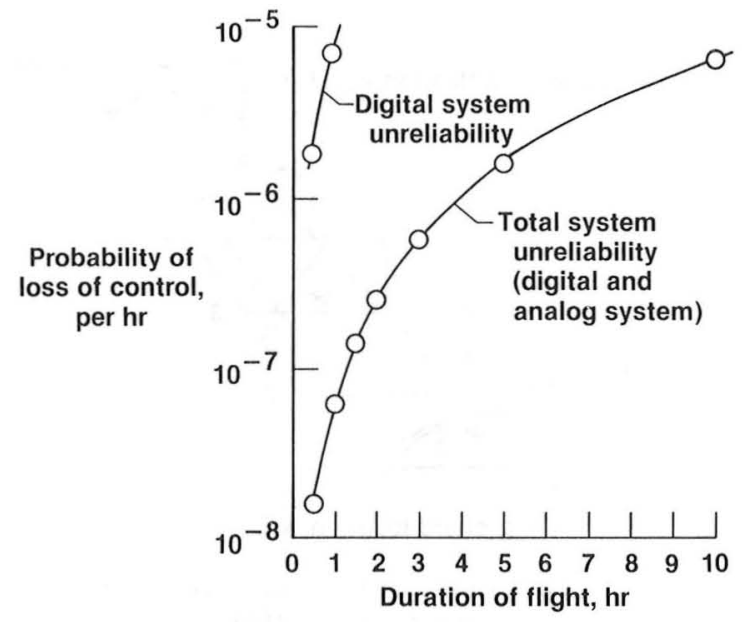

Fig. 17 Predicted reliability of $F-8$ DFBW system as built.

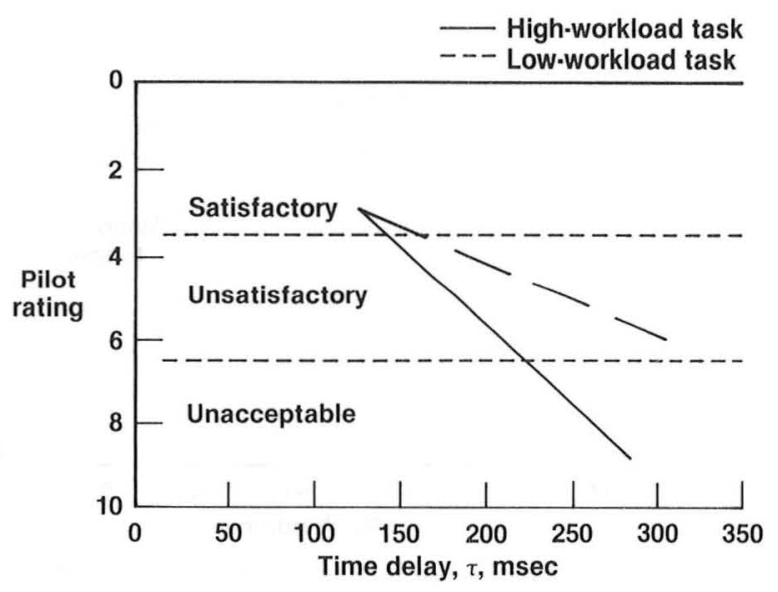

Fig. 18 Results of time-delay study for landing task with $F-8$ digital fly-by-wire aircraft.

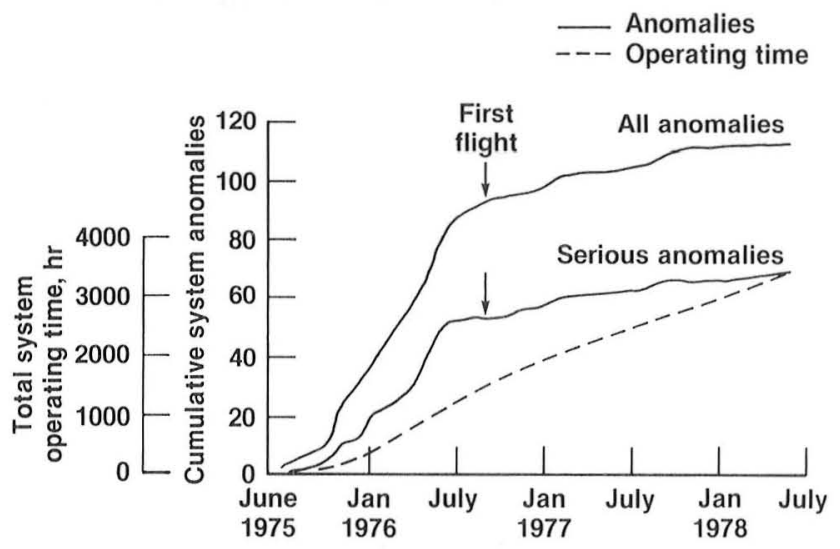

Fig. 19 F-8 DFBW system anomaly experience.

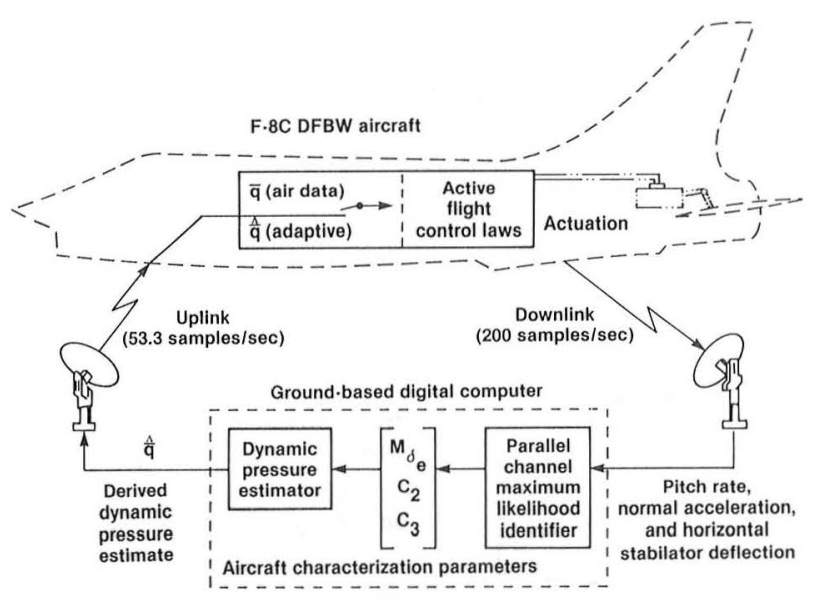

Fig. 20 Adaptive control flight test approach. 


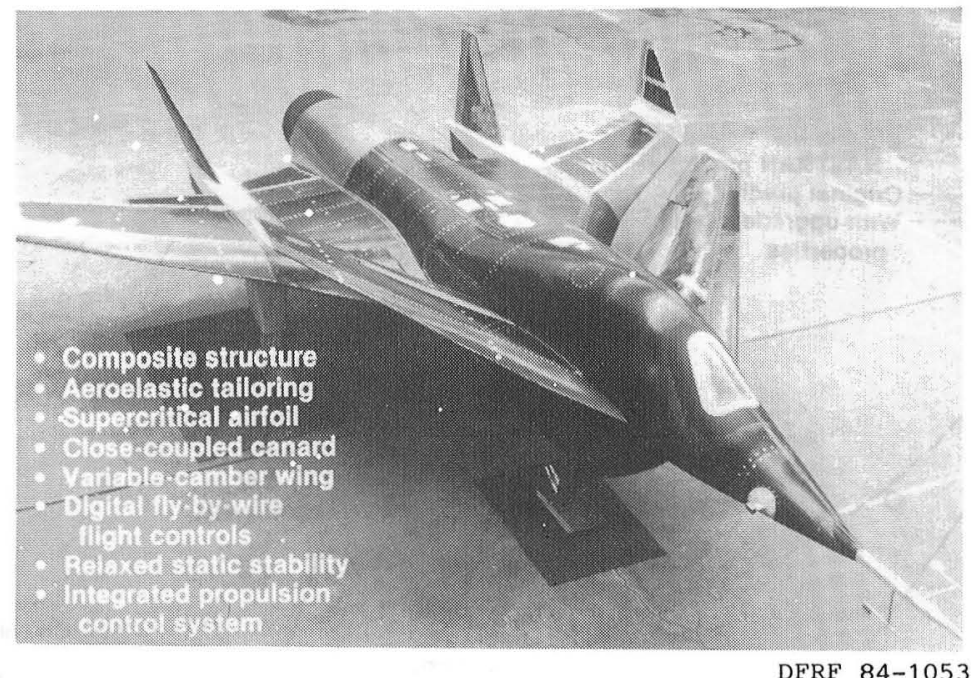

Fig. 21 Himat new technologies.

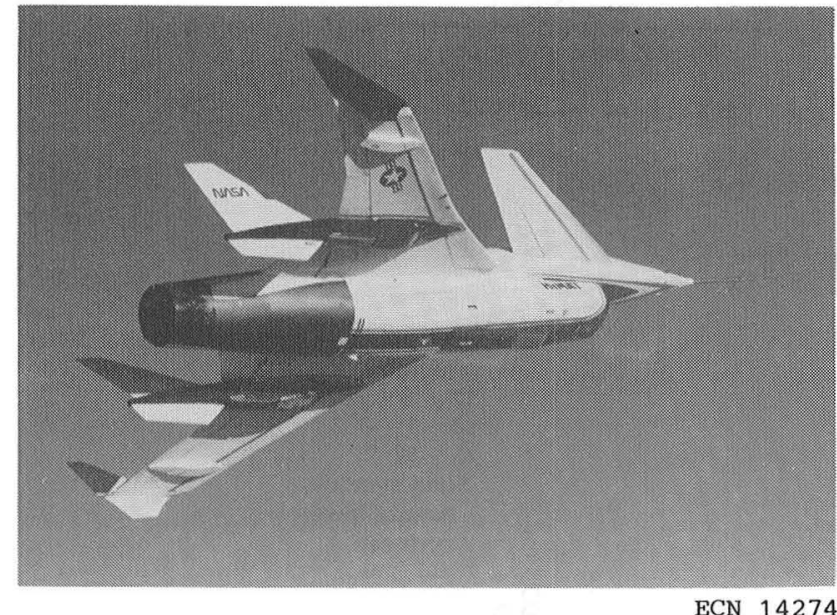

Fig. 22 HiMAT remotely piloted research vehicle.

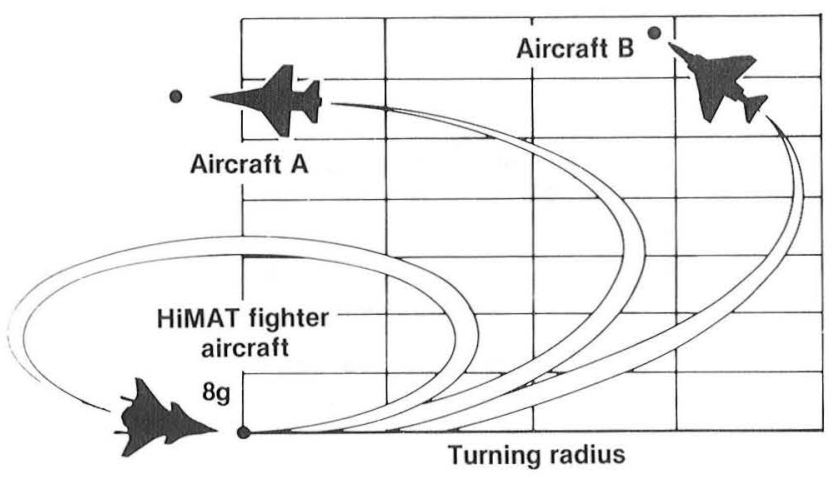

Fig. 23 Design maneuvering performance of the full-scale HiMAT aircraft.

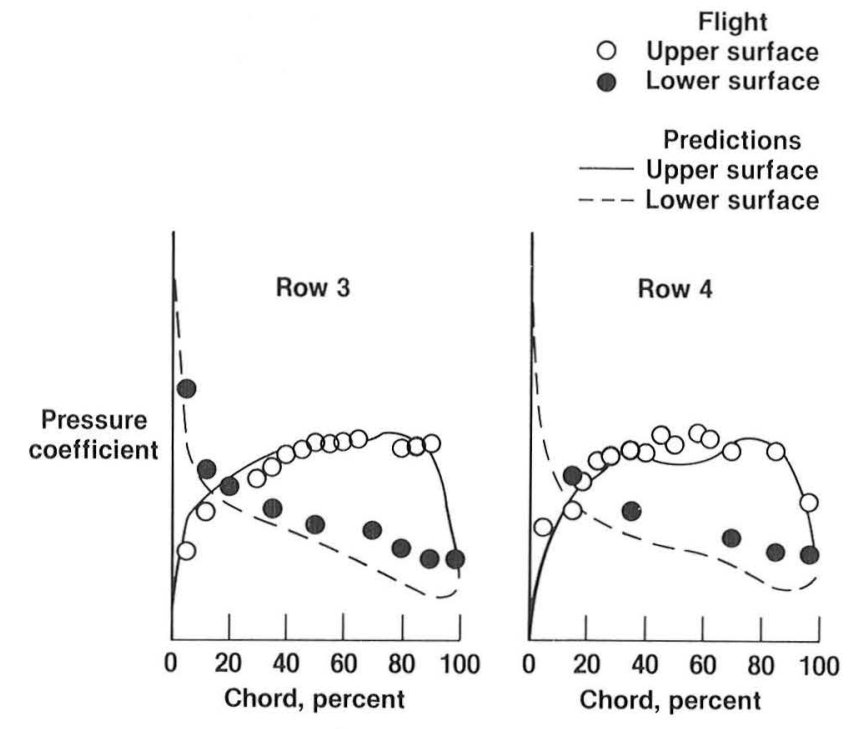

Fig. 24 HIMAT outboard wing pressure distributions. 


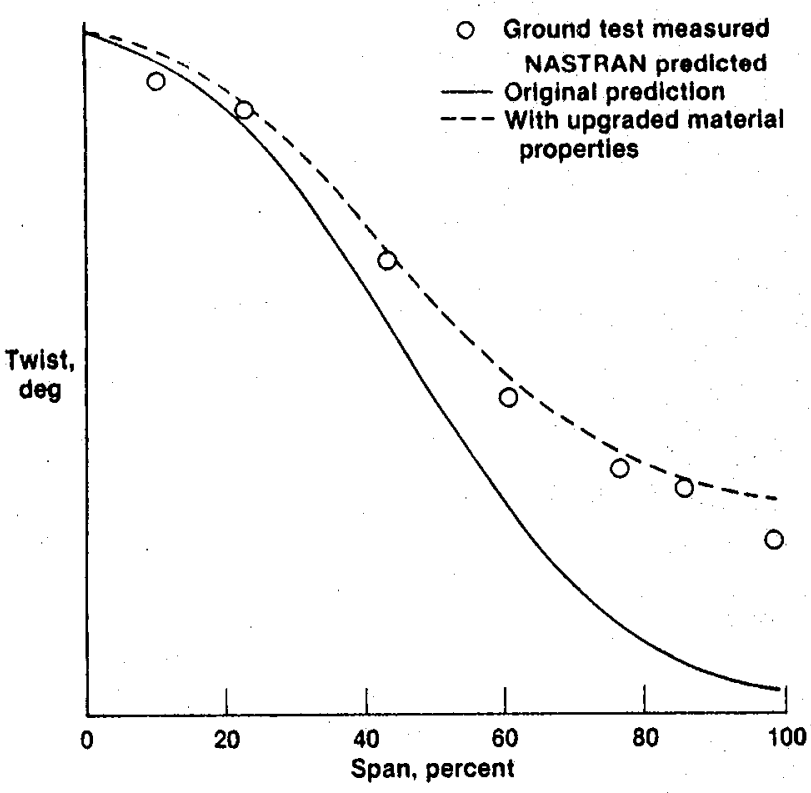

Fig. 25 HiMAT wing twist at transonic design point.

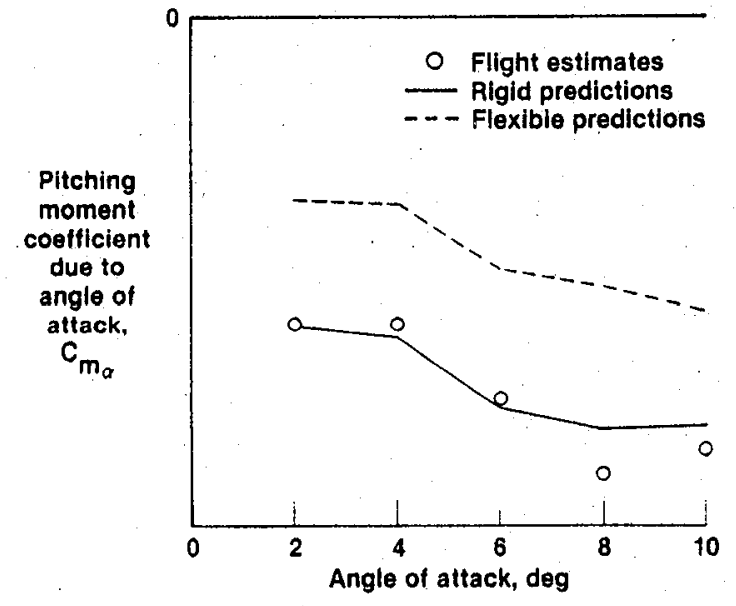

(a) Pitching moment coefficient.

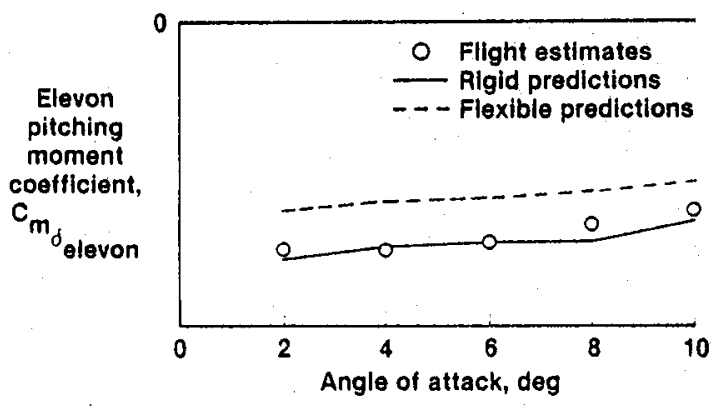

(b) Elevon pitching moment coefficient

Fig. 26 Variation of longitudinal coefficients with angle of attack at a Mach number of 0.9 . Maneuver leading edge; center of gravity $=0$ percent mean ae rodynamic chord.

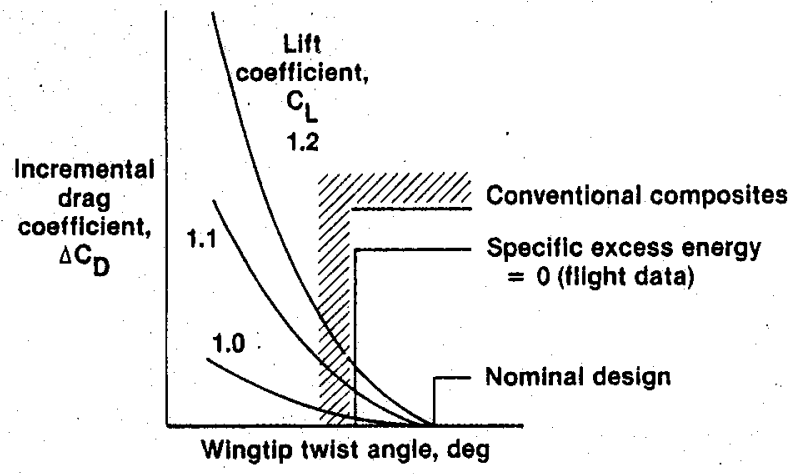

Fig. 27 Effect of wing twist on maneuver drag.

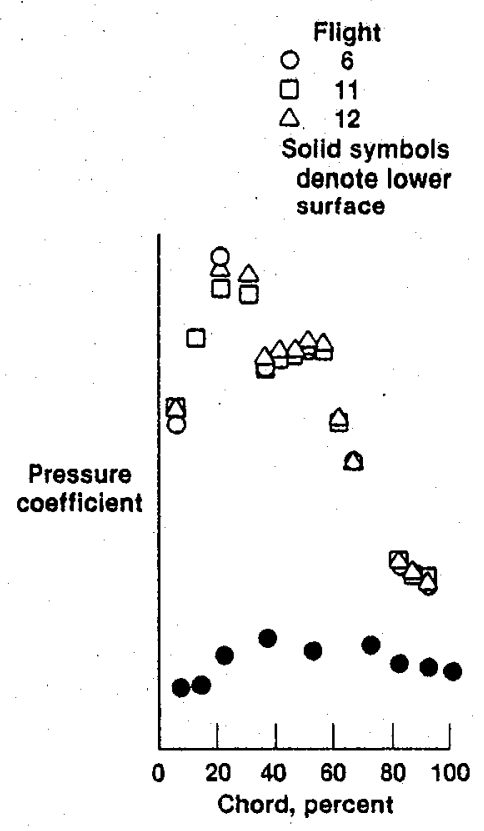

Fig. 28 HiMAT pressure distribution repeatability. 

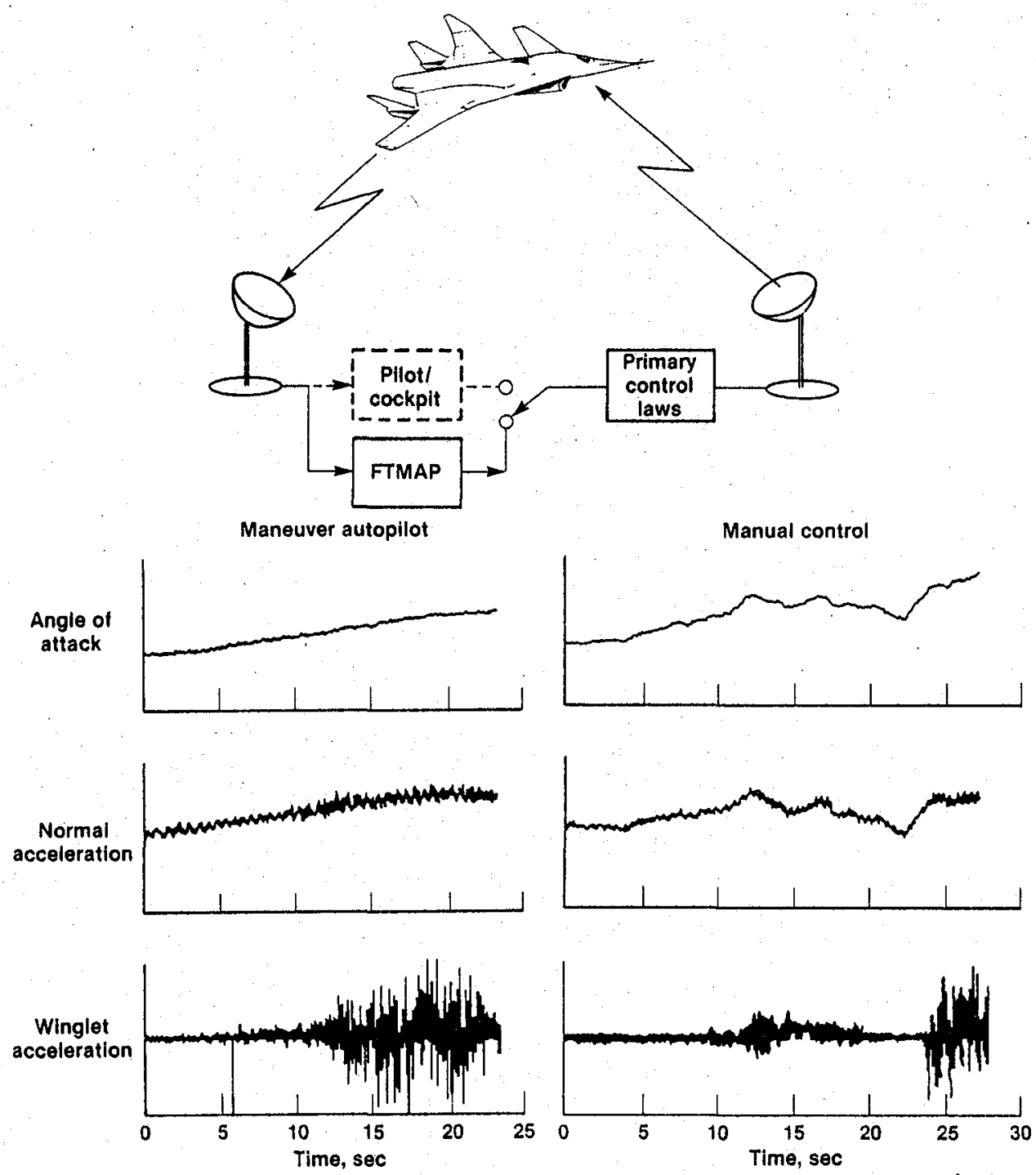

Fig. 29 HiMAT flight test maneuver autopilot (FTMAP).

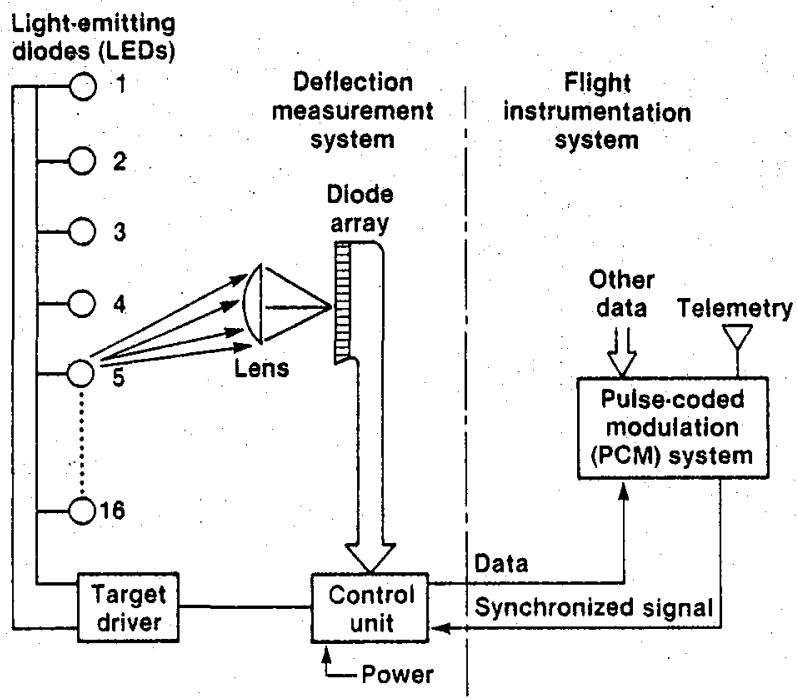

Fig. 30 Flight reflection measurement system for canard and wing. 


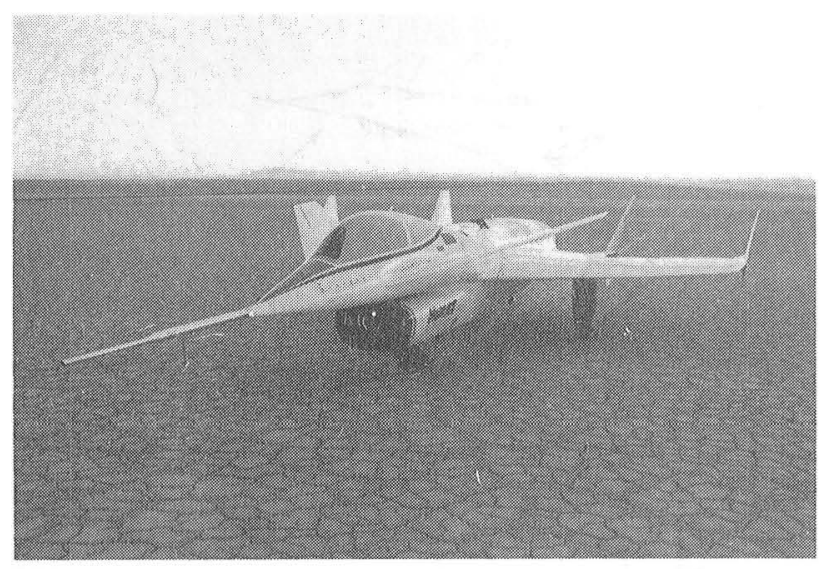

ECN 12055

Fig. 31 HiMAT vehicle on lakebed.

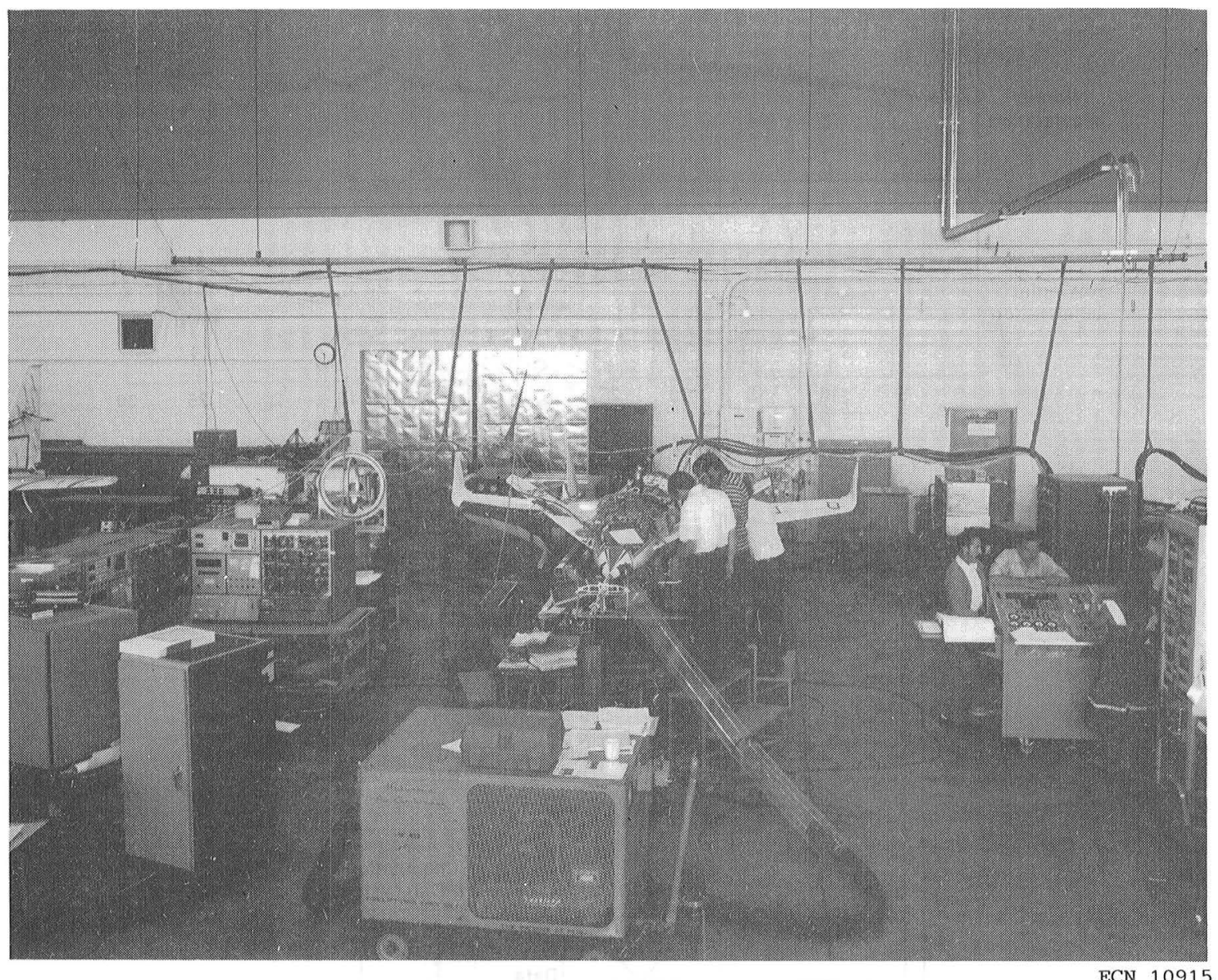

Fig. 32 HiMAT vehicle in iron bird configuration. 


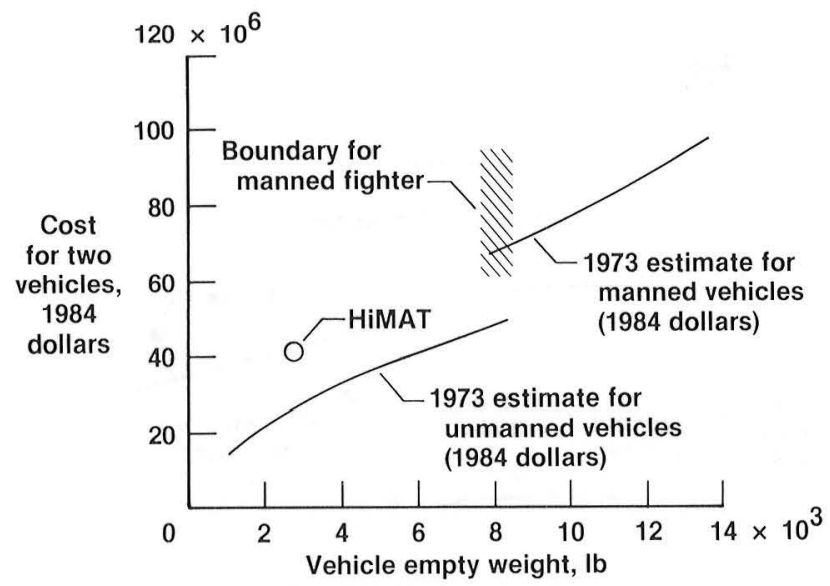

Fig. 33 Comparison of experimental aircraft costs.
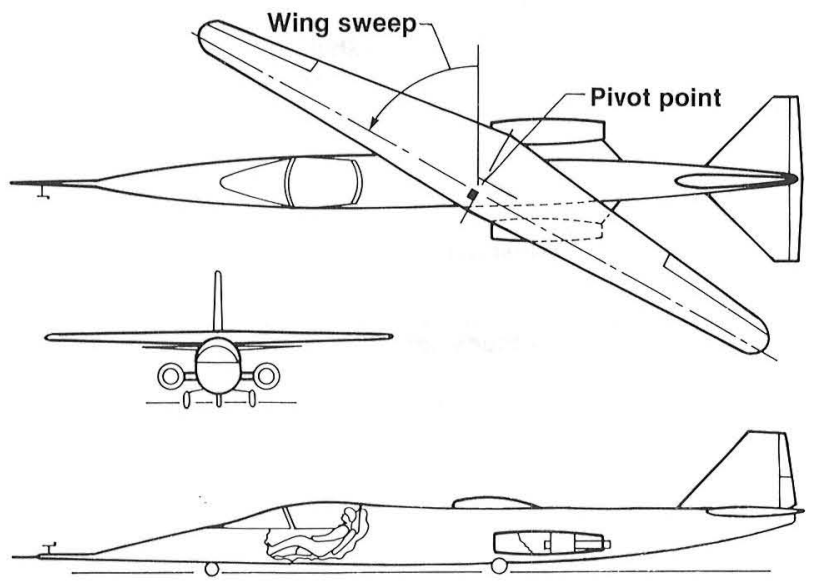

(a) General configuration.

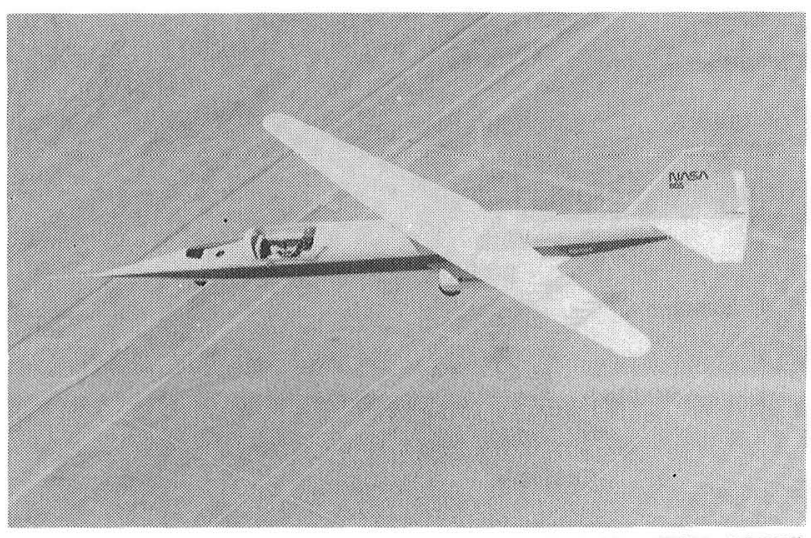

(b) In flight.

Fig. 34 AD-1 aircraft.

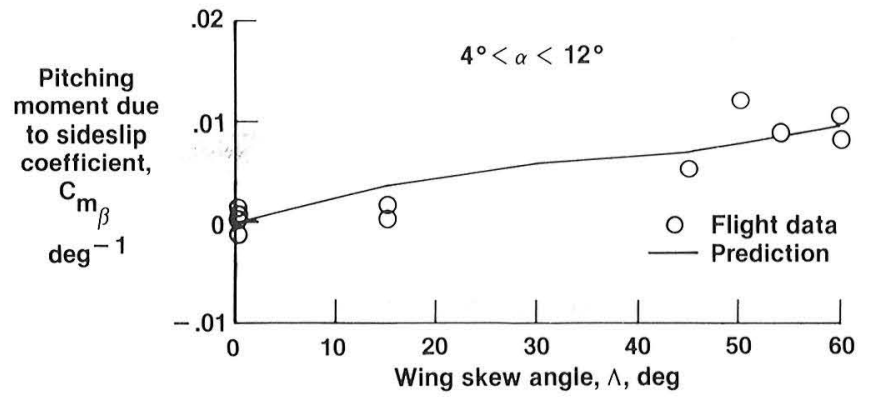

Fig. 35 Estimates of pitching moment due to sideslip coefficient as obtained from sideslip variation analysis.

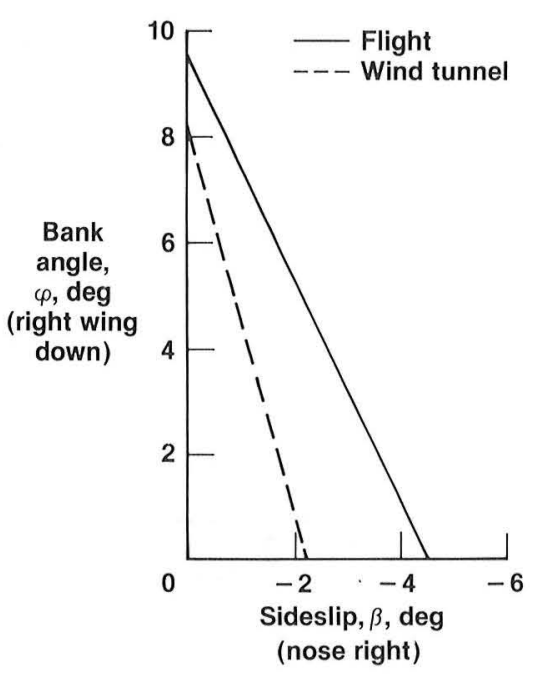

Fig. 36 Trim requirements at design point.

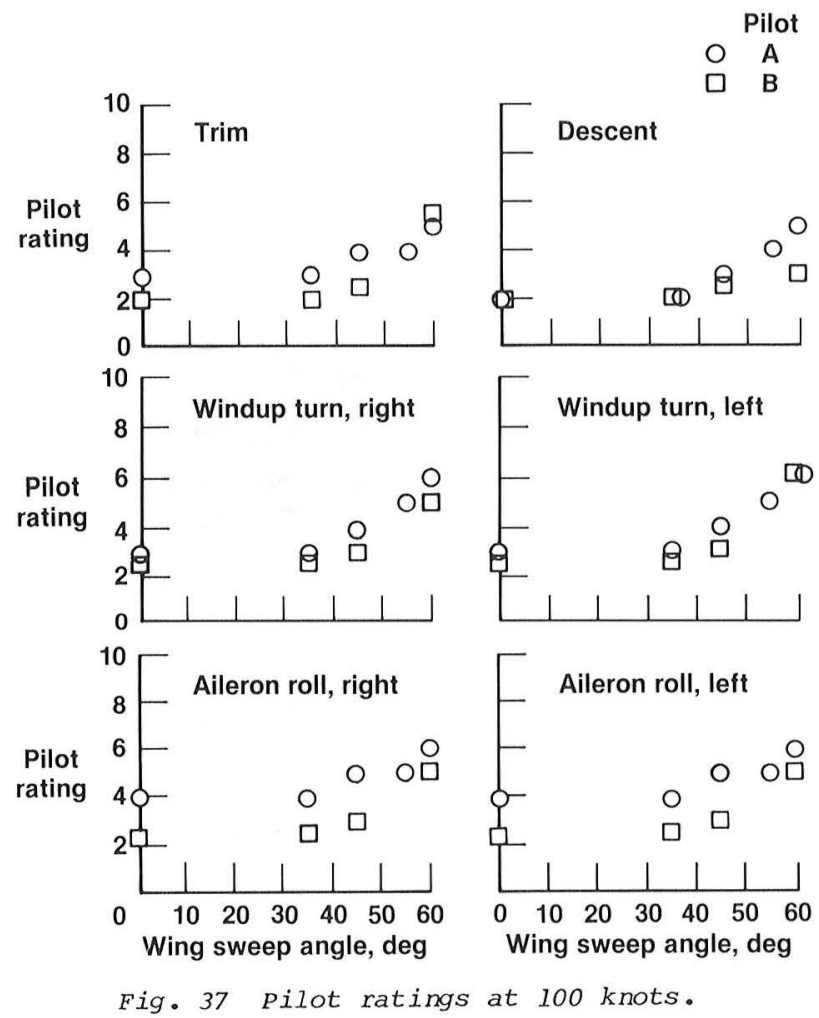



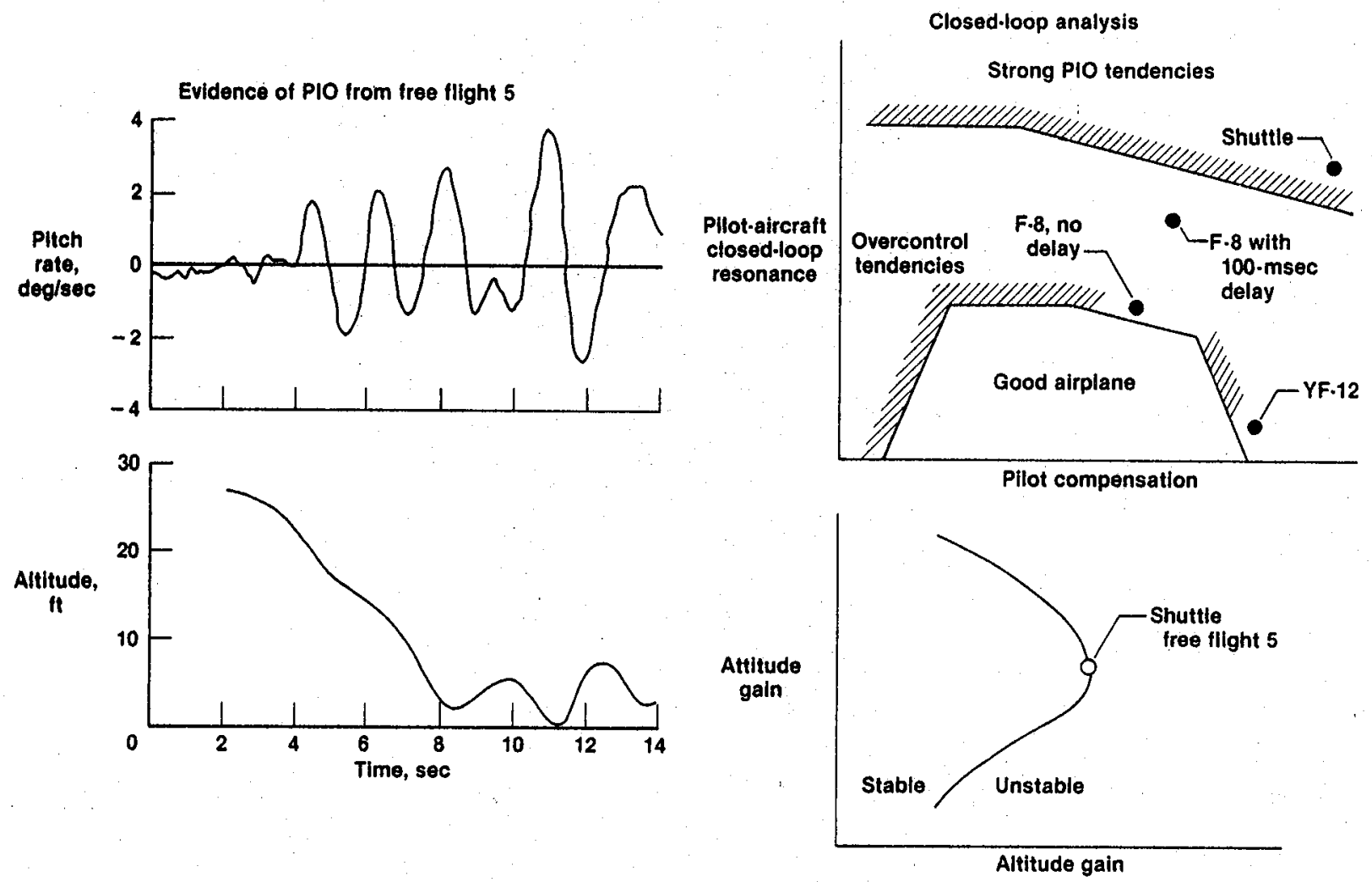

Fig. 38 Analysis of pilot-induced-oscillation (PIO) phenomenon.

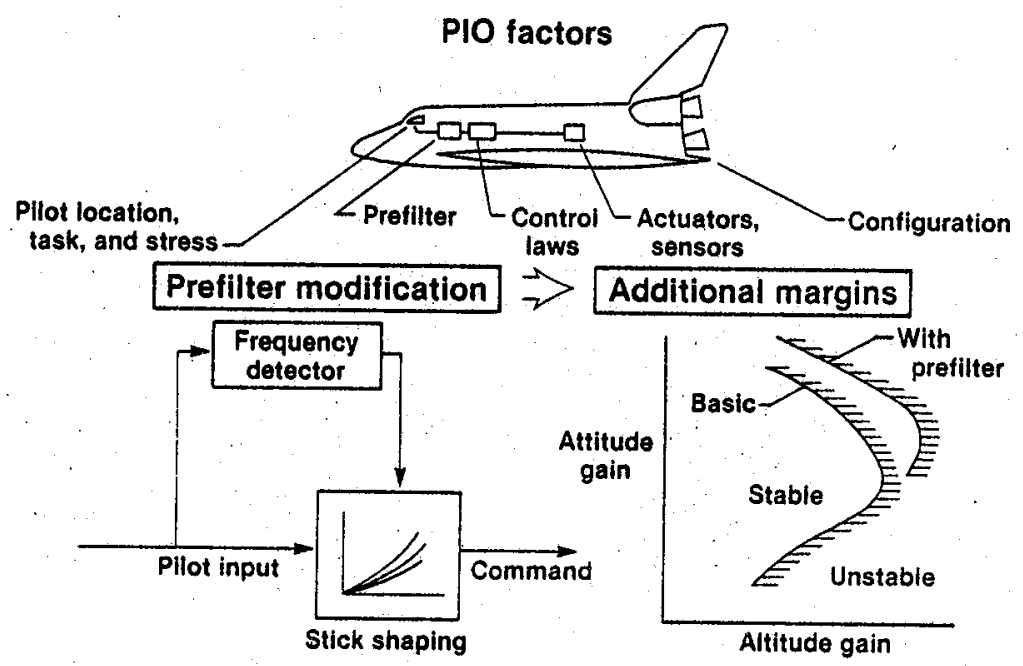

Fig. 39 Pilot-induced-oscillation suppression filter design. 

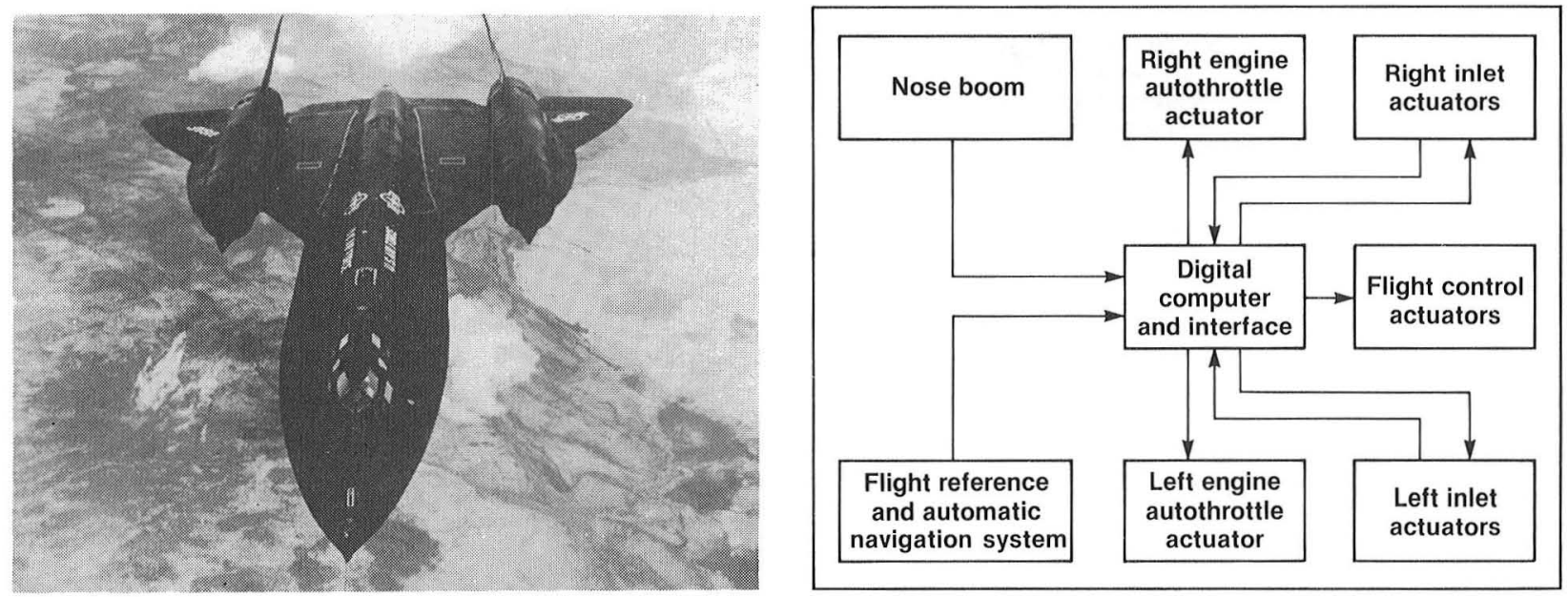

Fig. 40 Integrated propulsion flight control system.
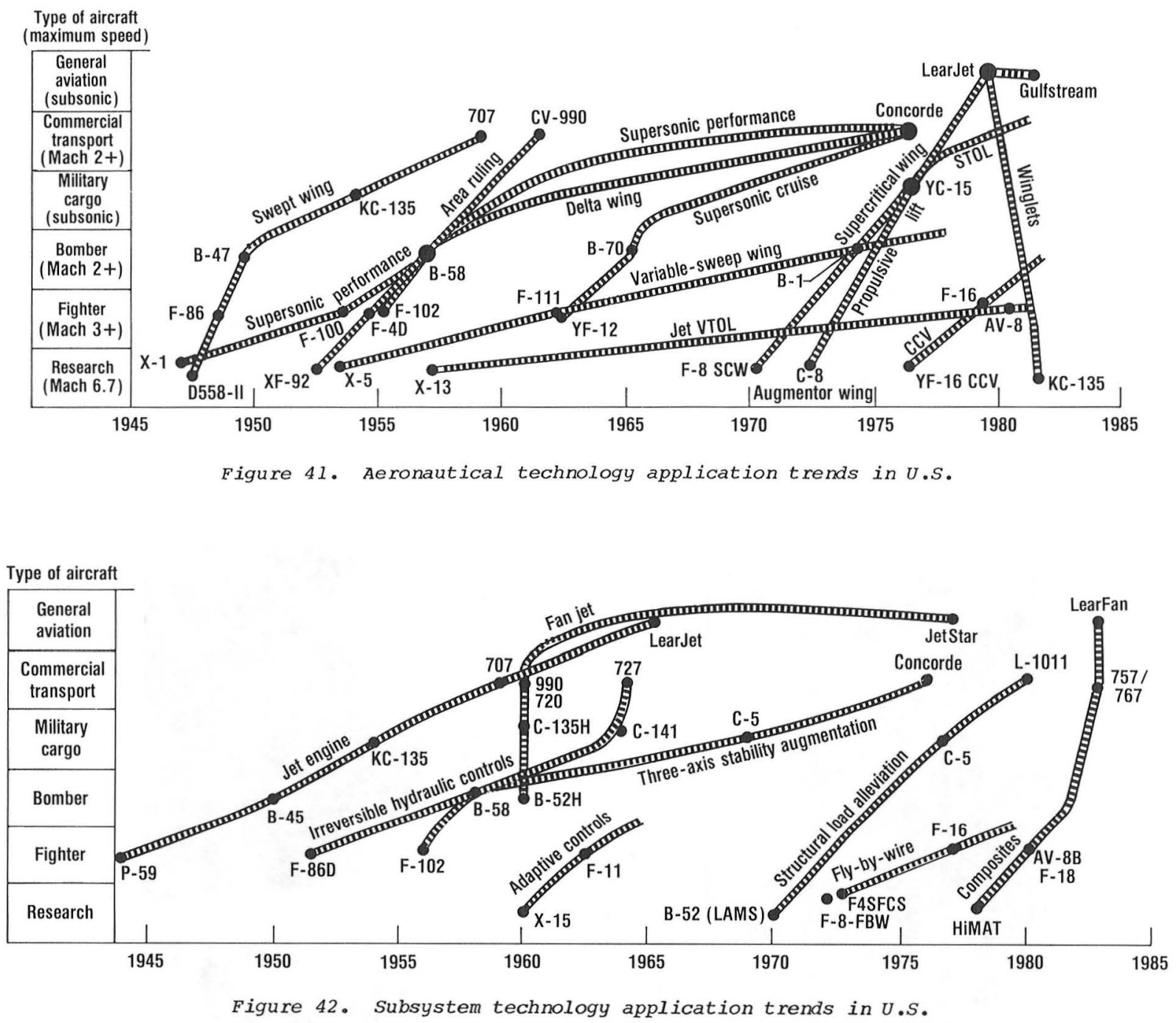


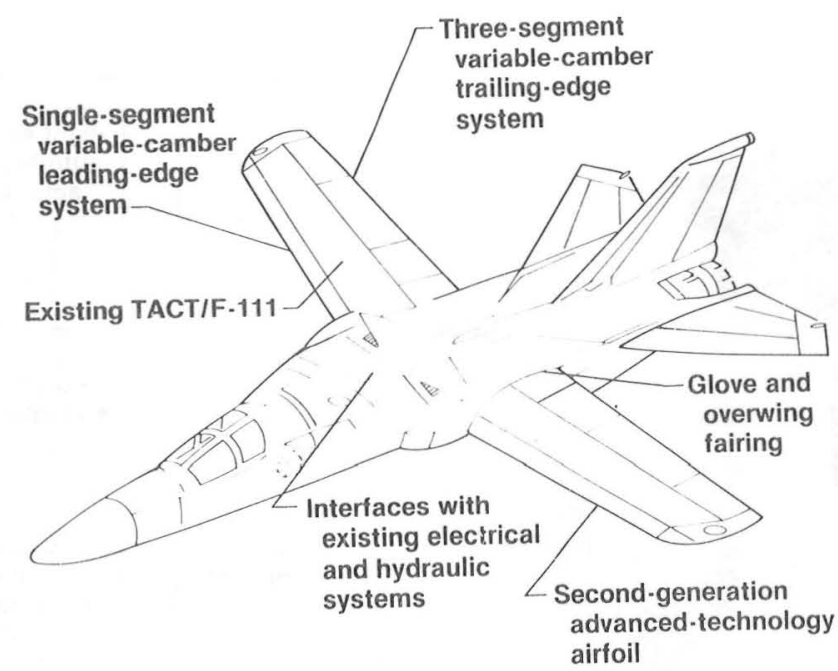

Fig. 43 AFrI/F-11. principal modifications.

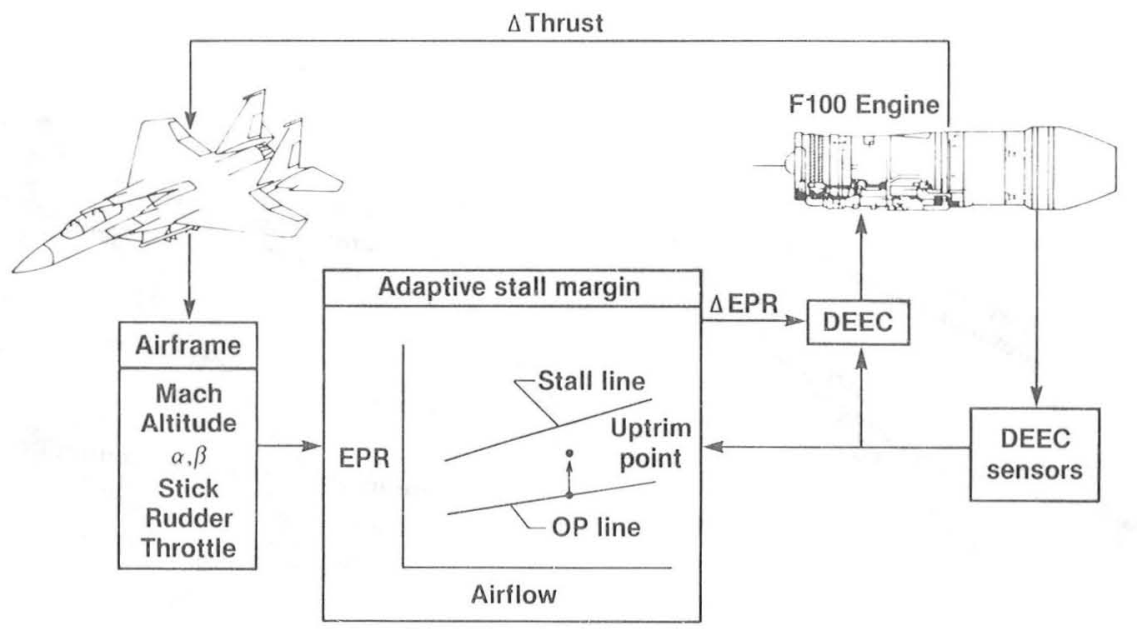

Figure 44. HIDEC adaptive engine control system.

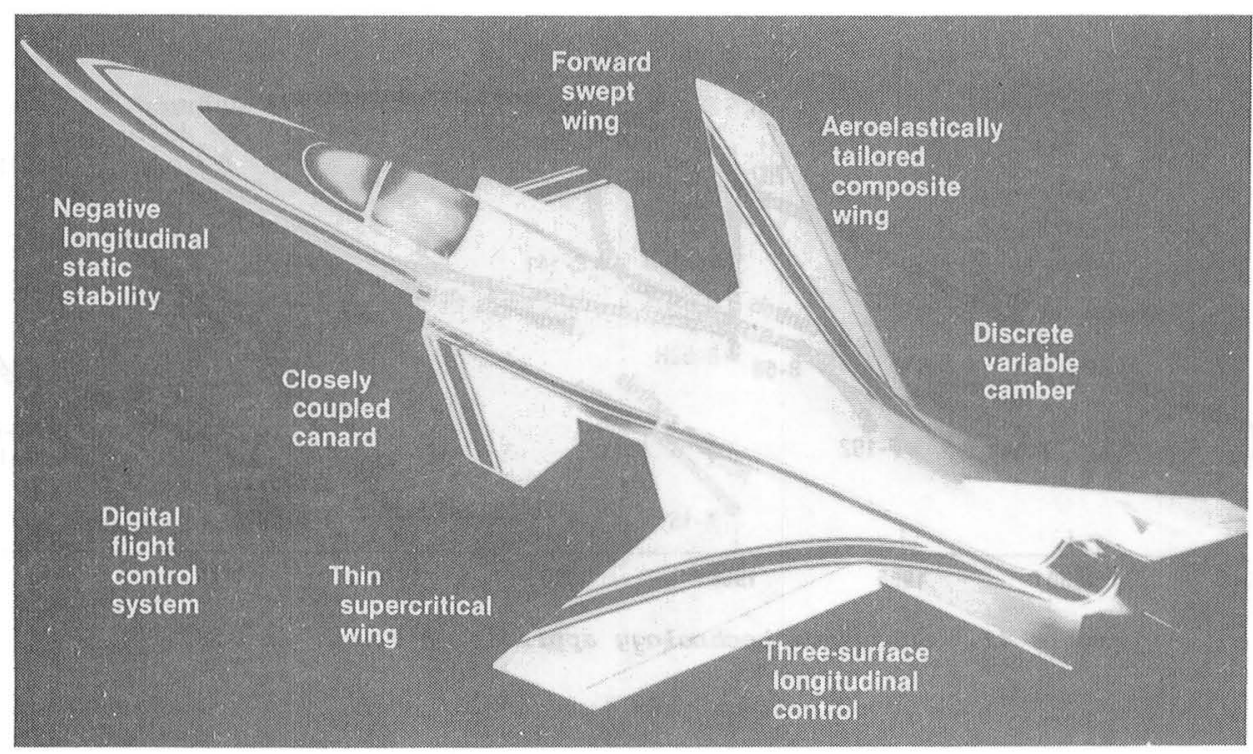

Fig. $45 \quad x-29$ advanced technologies. 


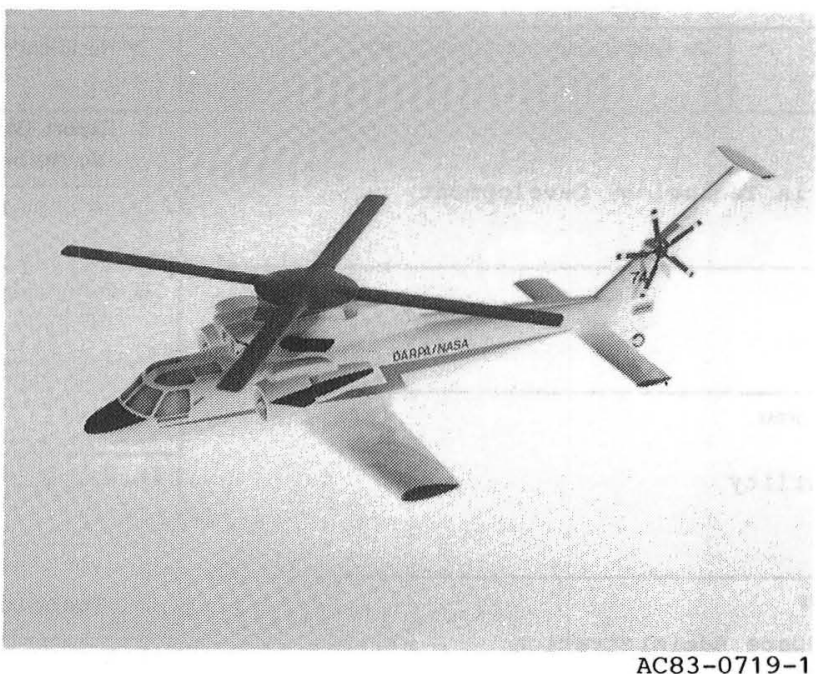

Fig. $46 \quad x$-wing aircraft.

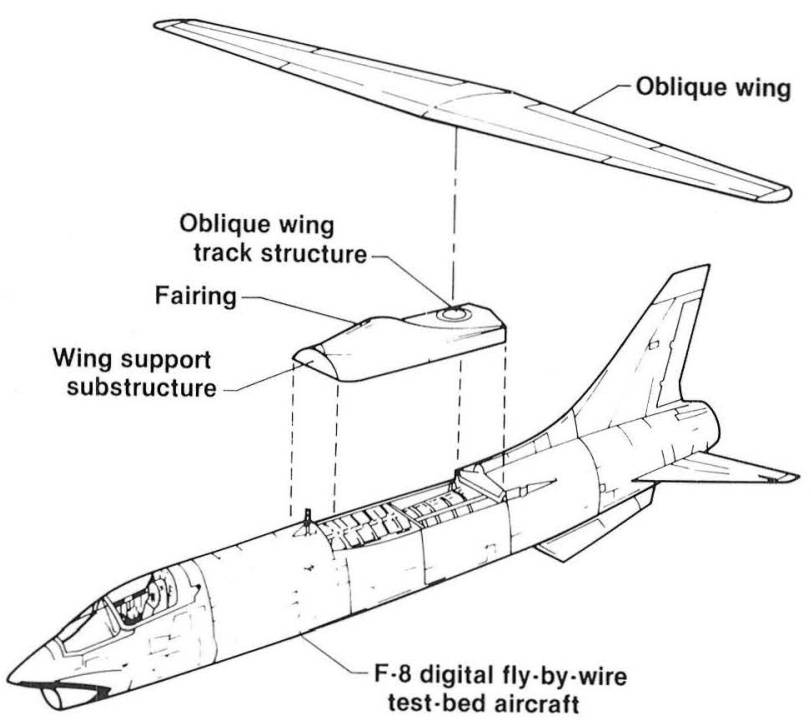

Fig. 47 proposed transonic oblique-wing research aircraft. 


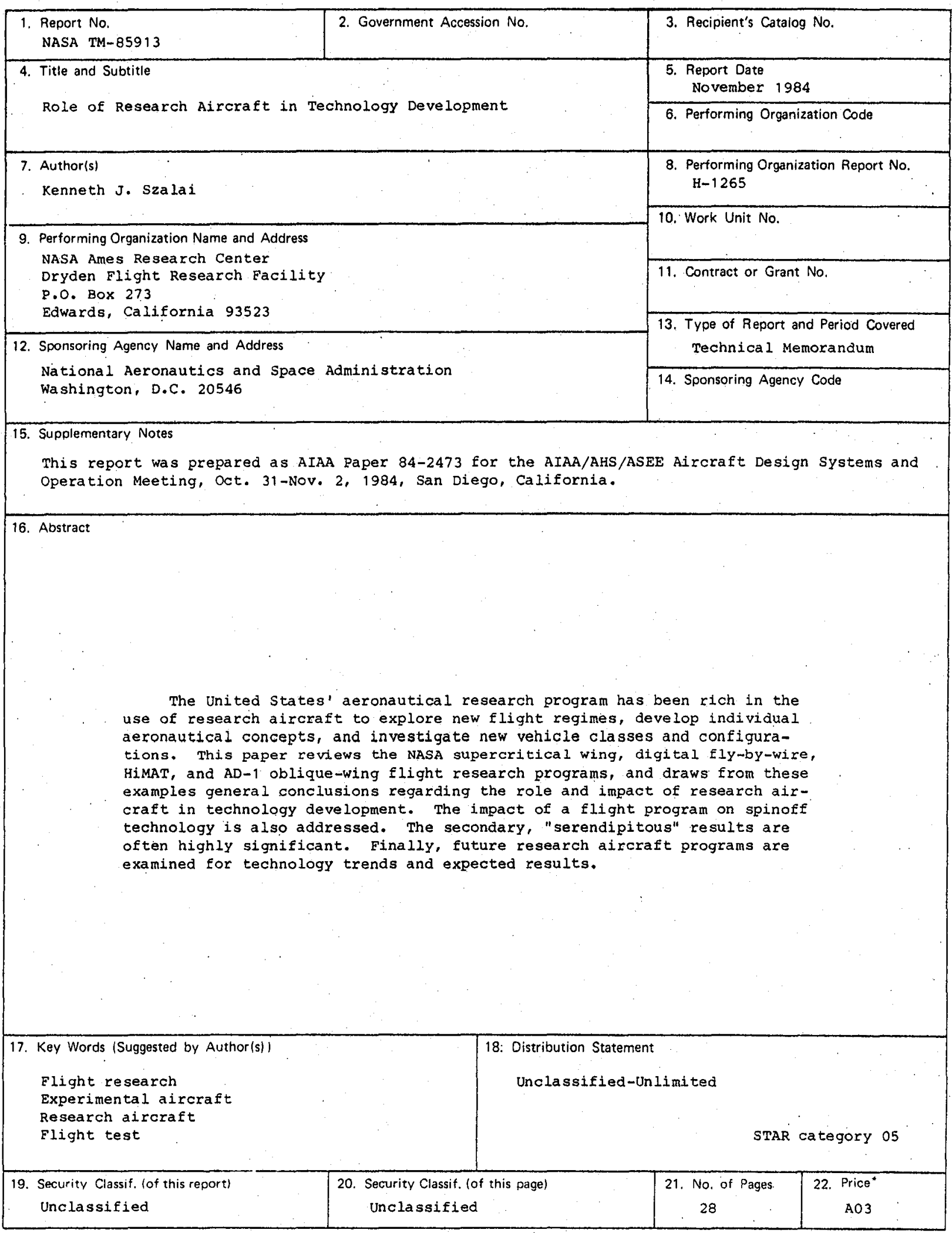

*For sale by the National Technical Information Service, Springfield, Virginia 22161. 


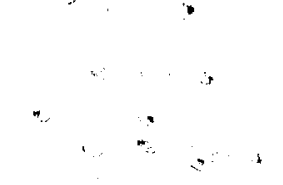


